111

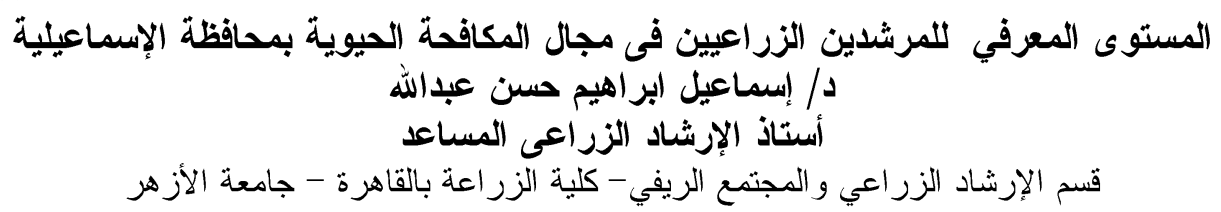

المستوى المعرفي للمرشدين الزراعين فى مجال المكافحة الحيوية بمحافظة الإسماعيلية

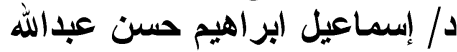

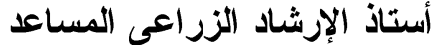

قسم الإرشاد الزر اعي و المجتمع الريفي- كلية الزر اعة بالقادرة الماعرة - جامعة الأزهر

استهد البحث تحديد المستوى المعرفي للمرشدين الزراعيين المبحوثين في مجال المكافحة الحيوية، وتحديد الطرق التدريبية التي يفضلها المرشدون الزرانيون اعيون المبحوثون للتثريب

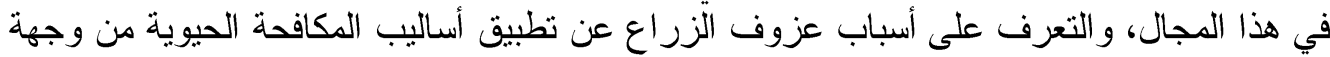

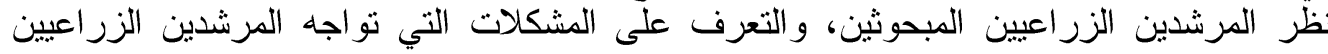
المبحوثين في هذا المجال، وتحديد العلاقة بين المتغيرات المدروسة للمرشدين الزراعين اعيين المبحوثين، وبين المستوى المعرفي لهم في مجال المكافحة الحيوية. وقد أجري البحث على عينة بلغ عددها 90 مرشداً زر اعياً في محافظة الإسماعيلية، وتم

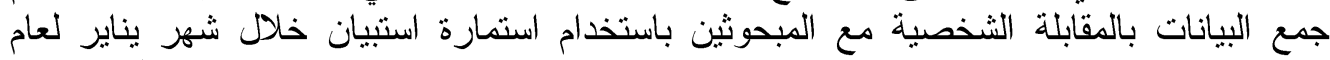

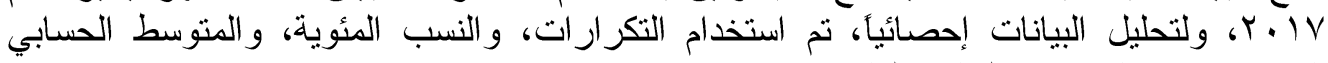

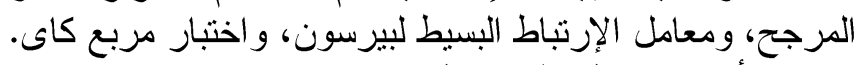

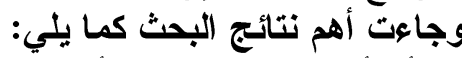

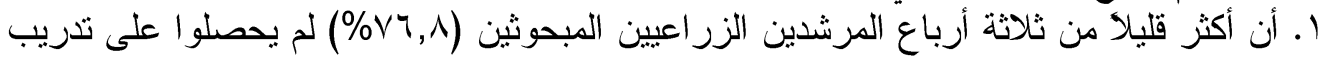

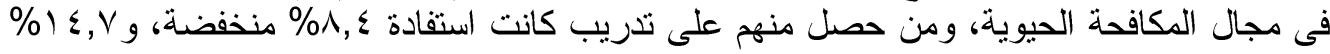
استفادتهم متوسطة.

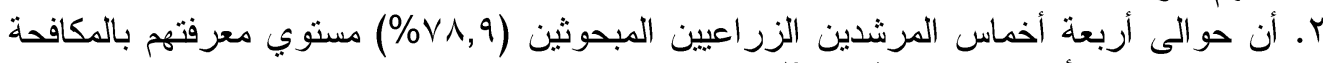

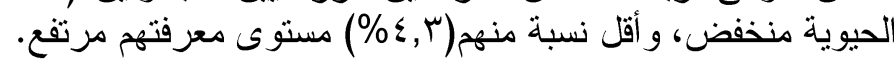

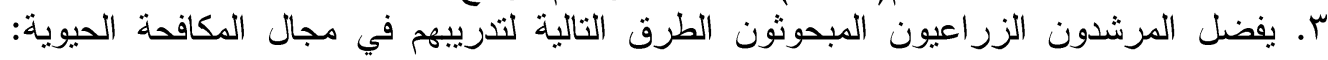

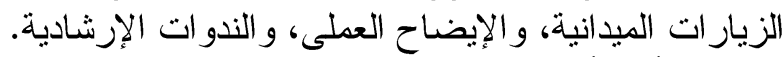
ء. من أهم أسباب عزوف الزراع عن استخدام المكافحة الحيوية من وجهة نظر المهرة المرشدين

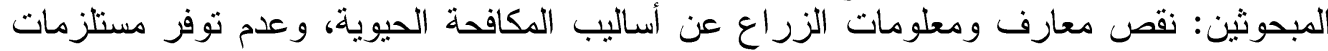

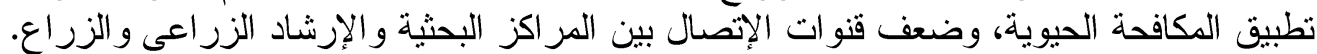

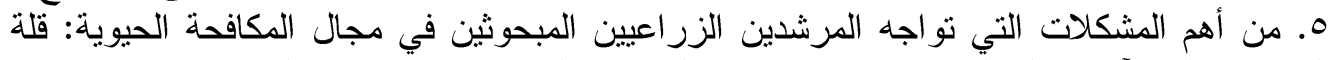

الحو افز و المكافآت، وقلة البر امج الإرشادية عن المكافحة الحيوية، و عدم توفر المعينات الإرشادية.

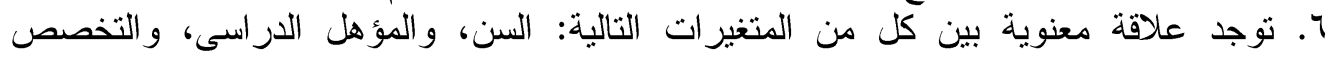

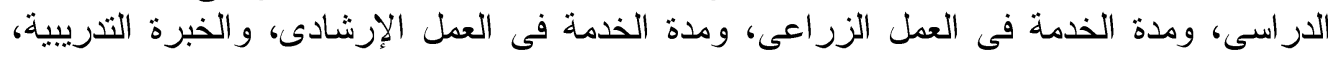
ودرجة الرضا الوظيفى للمرشدين الزراعيين المبحوثين، وبين المستوى المعرفي لهم فى مجال المكافحة الحيوية. مقدمة ومشكَة البحة البحث:

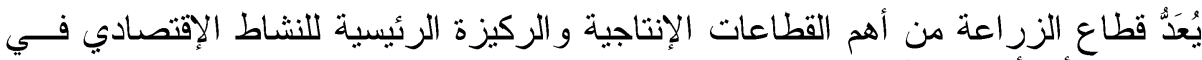

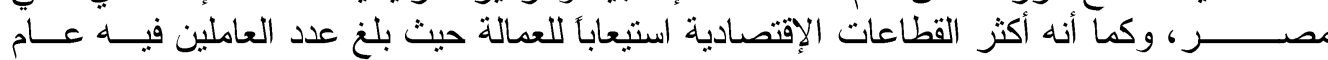

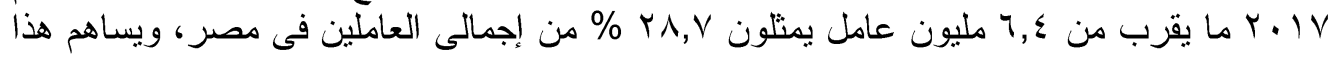

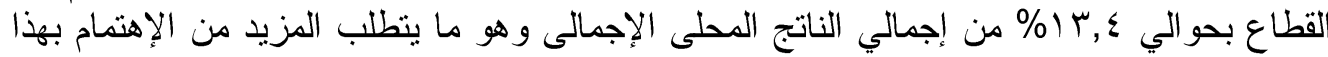

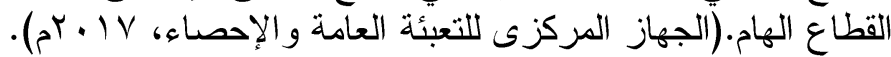

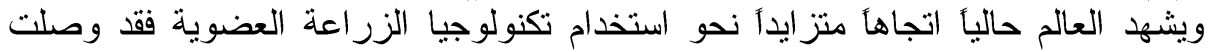
جملة المساحات المنزرعة عالمياً إلى حوالى مب مليون هكتار(فدان) ووصل حجم المبيعات . ؛

Fayoum J. Agric. Res. \& Dev., Vol. 32, No.2, July, 2018 
119

مليار دو لار فى عام ه . . ب، ولقد اتجه العالم إلى هذه التكنولوجيا مدفوعاً بالعديد من الأسباب منها

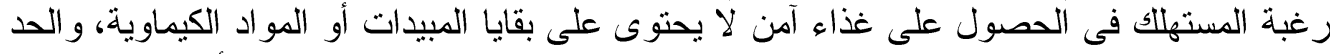

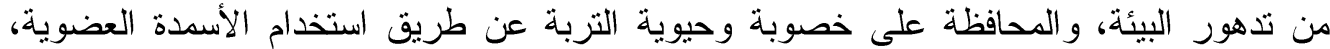

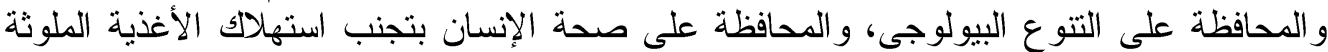

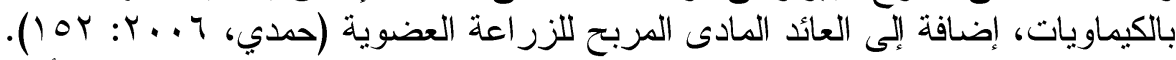

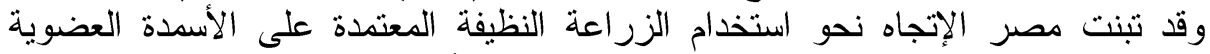

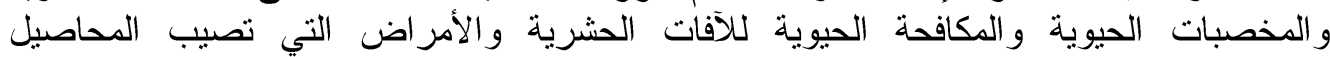

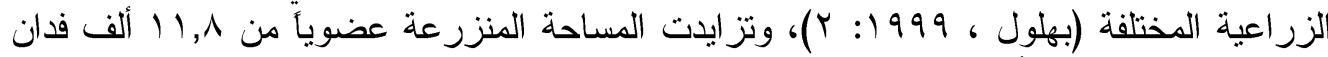

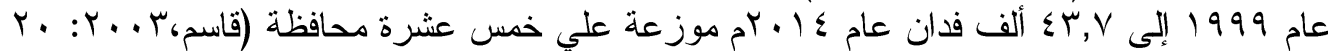

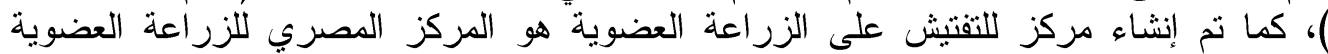
Center Of Organic Agriculture In Egypt

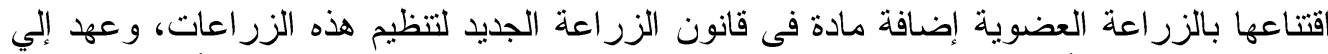

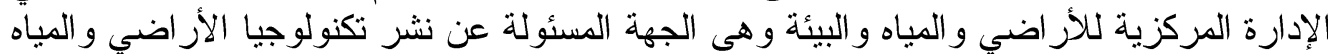

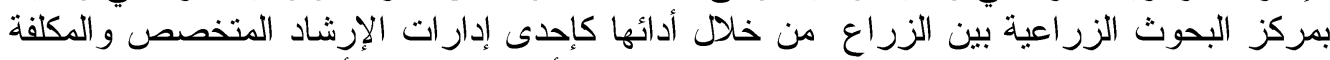

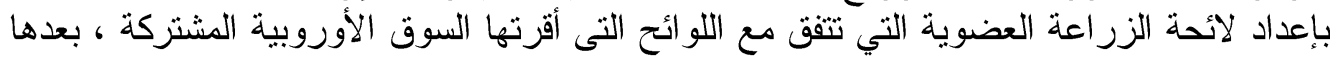

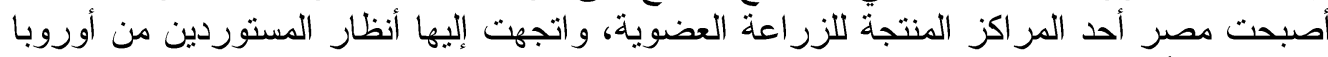

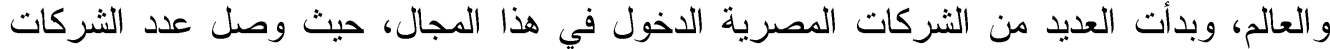

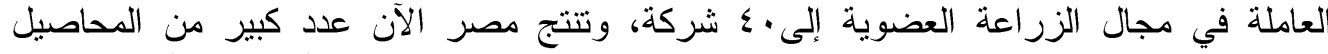

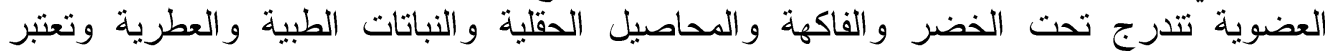

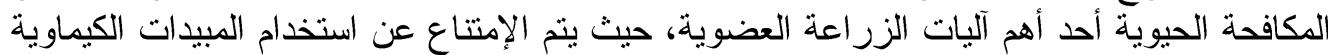

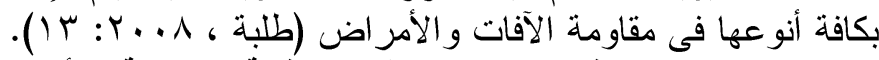

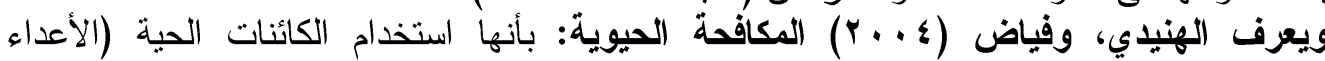

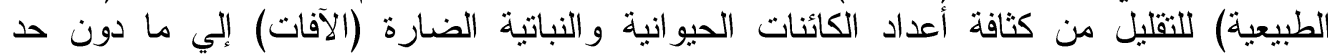

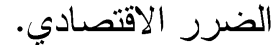
وللمكافحة الحيوية مميزات الفيل عديدة من أهمها: 1- أنها آمنة، لا تضر بالإلة الإنسان و البيئة.

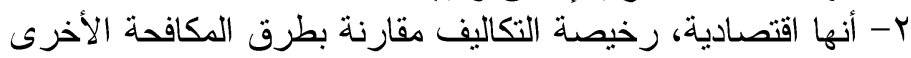

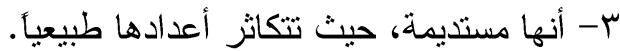

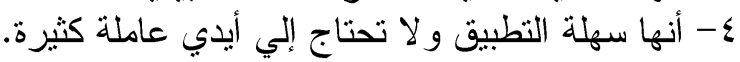

وللمكافحة الحيوية ثلاثة عناصر أساسية هى الطفيليات Parasitoids، والمفترسات Patedators، ومسبيات الأمراض Pathogen، ويمكن تتاول هذه العناصر الثلاثة على النحو التالى: لطئ

Parasitoids أولاً:- الطقيليات

هي ظاهرة يعيش فيها كائن حي داخل أو علي كائن حي آخر، يلازمه ويتخذى منه، ويسبب موته في النهاية. ويعرف الكائن المهاجم بالطفيل Parasitoid و الكائن الكَُّّهَّم عليه بالعائل Host

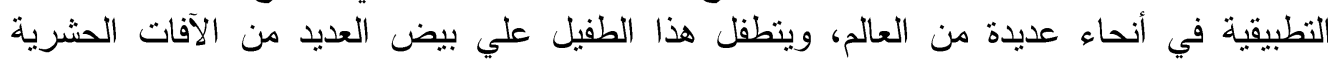

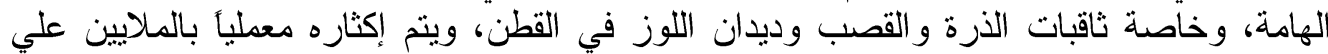

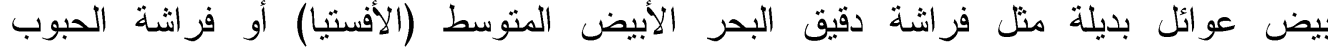

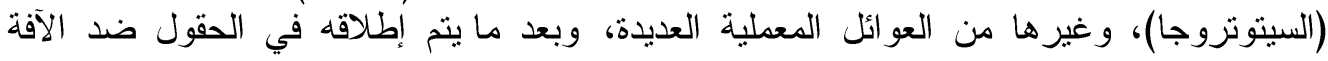

Fayoum J. Agric. Res. \& Dev., Vol. 32, No.2, July, 2018 
$1 Y$.

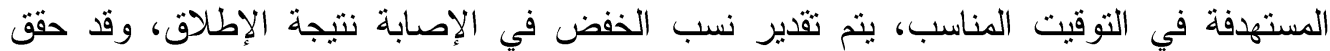

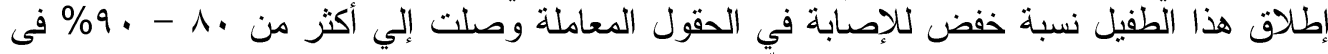

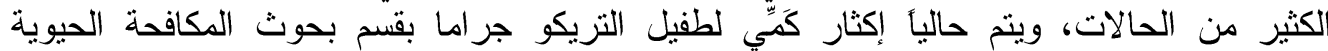
بالجيزة حيث يستخدم بنجاح في مكافحة ثاقبات القصب الصغيرة، وهى الآفة الرئيسية التي تهدد

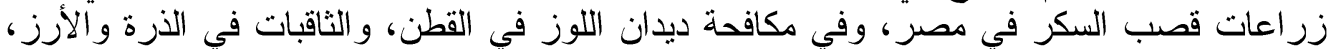

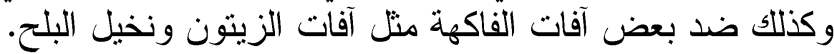

ثنانياً:- الافتر اس: Predation

و هو ظاهرة مهاجمة كائن حي لكائن حي آخر بغرض التغذي عليه لفترة محدودة، ثم ينتقل

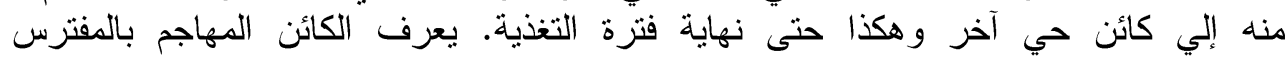
Predator والأكاروسات وبيض ويرقات العديد من العو ائل، وقد تركزت غالبية استخدامات المفترسات ضد ضد آفة ولة

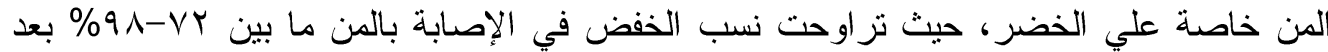
أيام قليلة من الإطلاق، و أيضاً مثل خنفساء الكالوسوما و التي تهاجم ليلا يرقات التئ حرشفية الأجنحة و العذارى الموجودة في التربة (منل يرقات، وعذارى دودة ورق القطن وغيرها من حرشفية (الأجنحة).

نالثاً:- المسبب المرضي: Pathogen

وهو كائن حى دقيق مُمرض يسبب موت الحشرات نتيجة للإصابة المرضية، ومن أمثلتها

البكتيريا Bacteria و الفيروس Virus و الفطر Fungous و البروتوزوا Protzoa و النيماتودا Nematoeds وتتو اجد الكائنات الدقيقة مثل البكتيريا و الفطر و الفيروس والبروتوزوا و النيماتودا

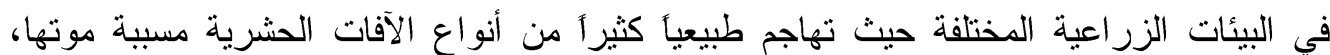

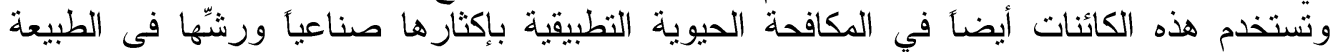
بنفس طرق رشّ المبيدات فتتشر العدوى بين الحشرات وتفتك بها نتيجة التغذية علي الأجزاء النباتية الملوثة بجر اثيم هذه المسبيات مُحدثة العدوى عن طريق المعدة أو من خلائل الثخور التنفسية.

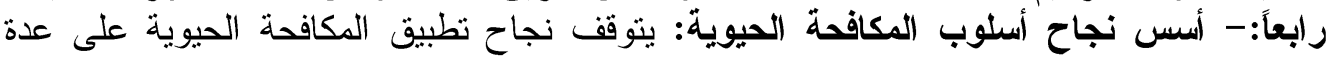

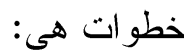
1- التعريف الصحيح بأنواع الآفات المستهدفة و أعدائها الطبيعية. r- الإلمام الجيد بالنواحي البيولوجية و البيئية الخاصة بالآفة وألئة أعدائها الحيوية من حيث نشاطها و انتشار هما وكفاءتهما.

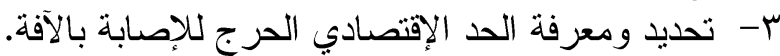

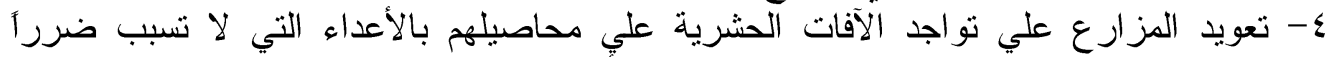
إقتصادياً، بل تكون عاملاً مشجعاً علي جذب الب وتكاثر الأُعداء الطبيعية في حقله.

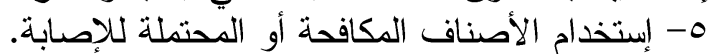
؟- إستخدام طرق المكافحة الزر اعية و الميكانيكية أطول فترة الافة ممكنة.

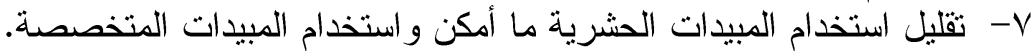
- ثأخير عمليات المكافحة الكيماوية ما أمكن.

9- - إختيار العدو الحيوي المناسب للإستخدام في مكافحة الآفة أو الآفات سواء في الزبة الزراعات

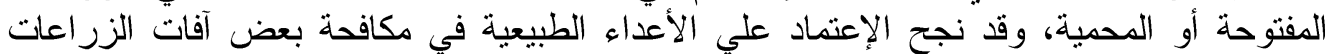
المحمية كلية في بعض الحالات

Fayoum J. Agric. Res. \& Dev., Vol. 32, No.2, July, 2018 
$|r|$

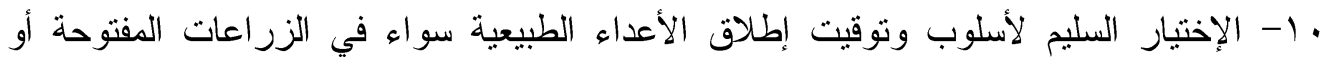

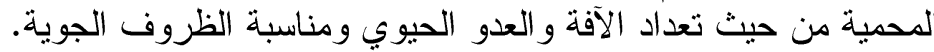
وإض التيقيم الدقيق لنتائج الإطلاق للحكم علي نجاح أسلوب المكافحة الحيوية من عدمه. (الهنيدي،

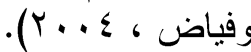

وهنا تبرز أهمية الإرشاد الزراعى باعتباره جهازأ تعليمياً وخدمياً يهذف لحل مشكلة

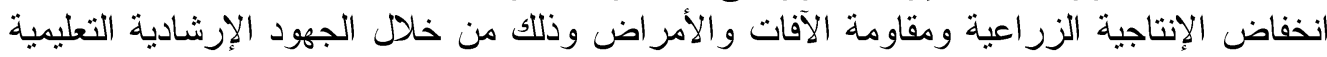

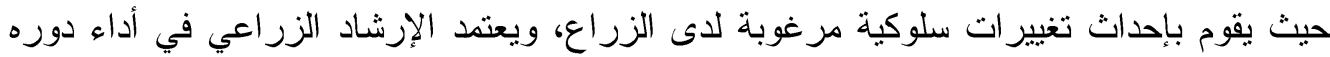

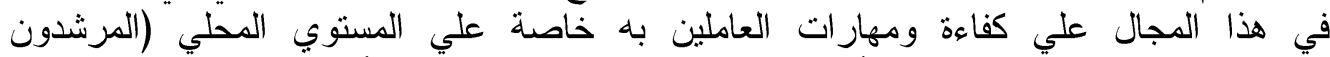

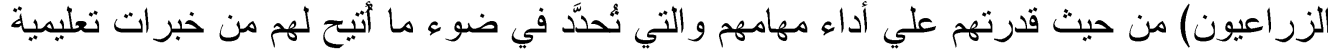

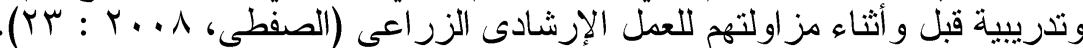

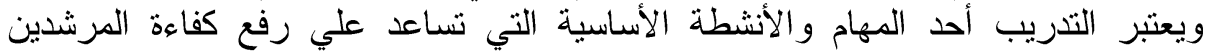

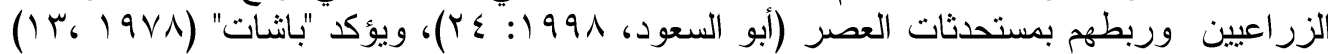

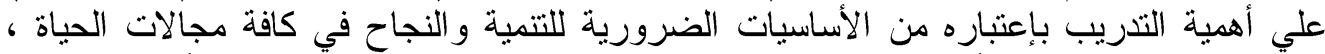

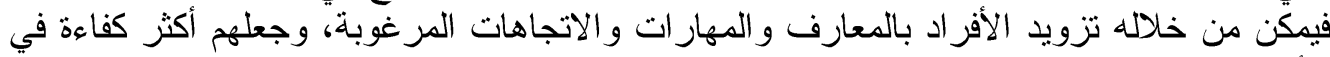

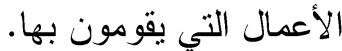

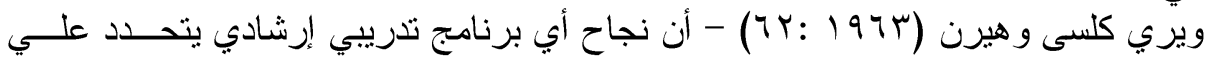

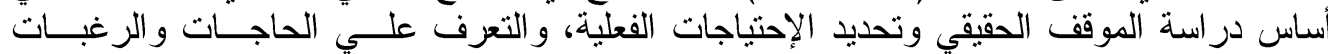

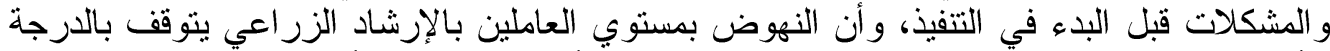

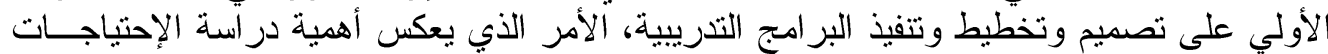

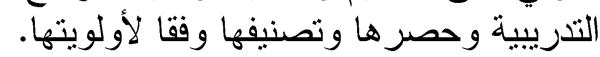

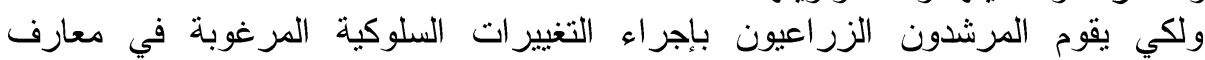

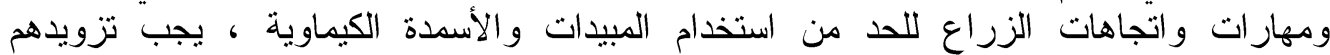

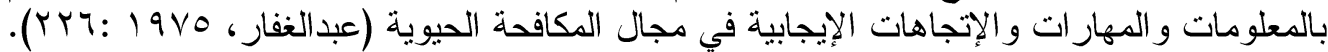

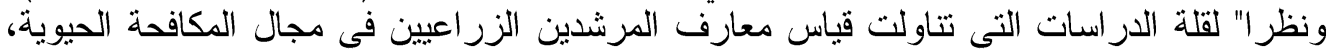

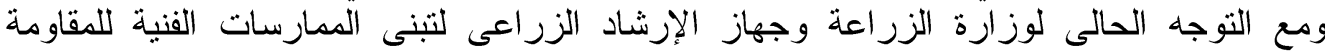

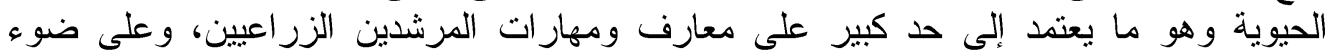

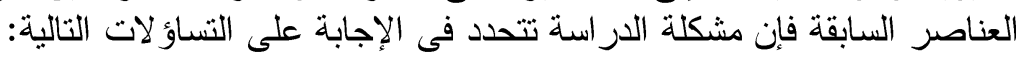

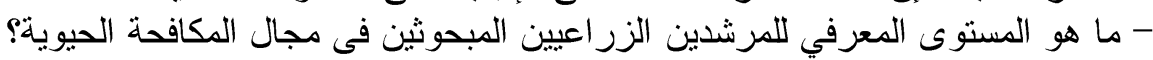

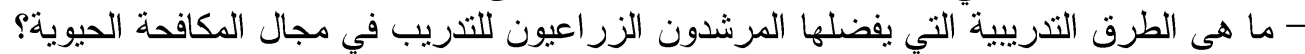

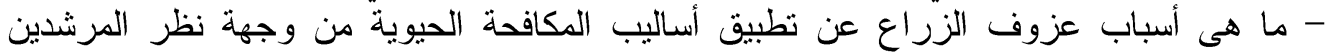

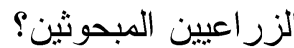

- ما هى المشكلات التي تو اجه المرشدين الزر اعيين المبحوثين في مجال المكافحة الحيوية؟ المئج

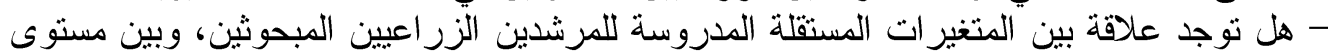

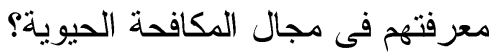

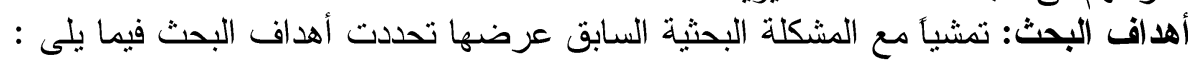

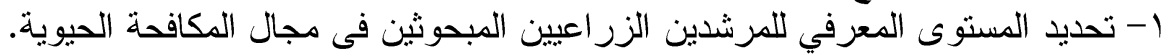

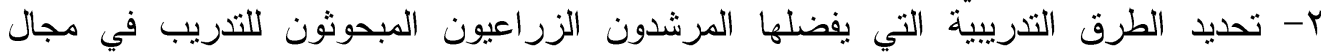

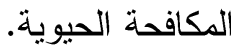
ب- التعرف على أسباب عزوف الزئل الزراع عن تطبيق أساليب المكافحة الحيوية من وجهة نظر المرشدين الزر اعيين المبحوثين. ع- التعرف على المشكلات التي تو اجه المرشدين الزين الزراعيين في مجال المكافحة الحيوية.

Fayoum J. Agric. Res. \& Dev., Vol. 32, No.2, July, 2018 
ه- تحديد معنوية العلاقة بين المتغيرات المستقلة المدروسة للمرشدين الزراعيين المبحوثين، وبين المستوى المعرفي لهم مجال المكافحة الحيوية.

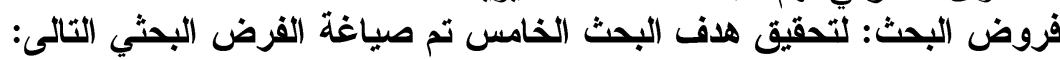

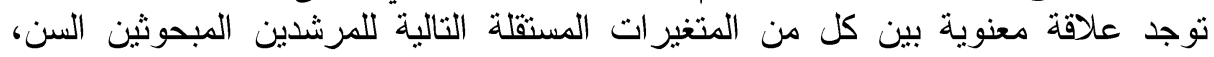

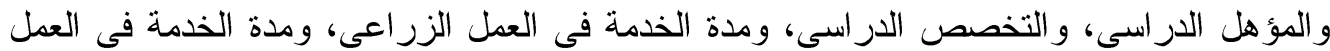

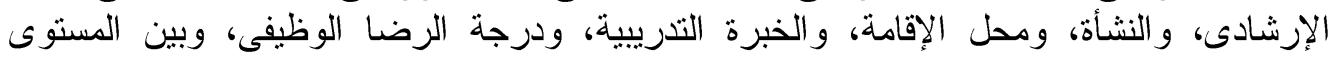

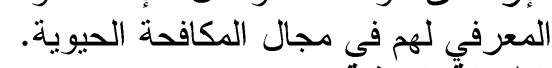

تعتبر محافظة الإسماعيلية من المحافظات الهامة فى إنتاج وتصدير الخافير الخضر

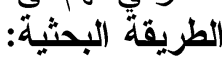

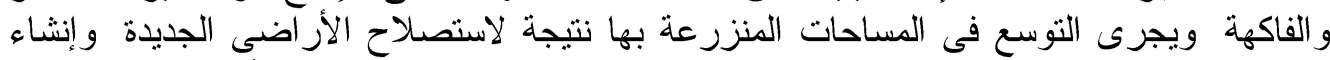

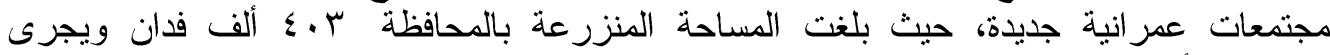

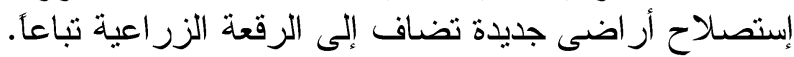

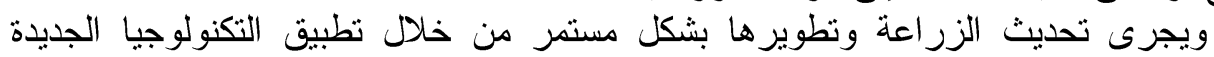

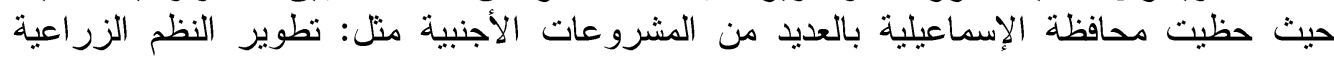

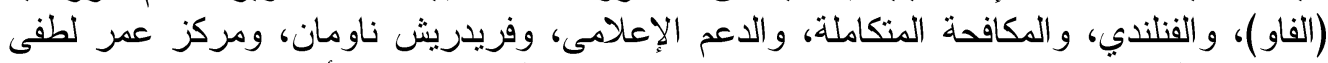

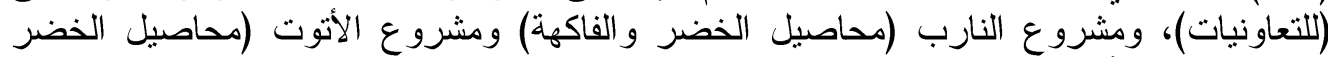

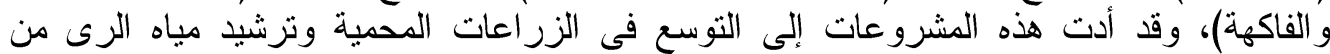

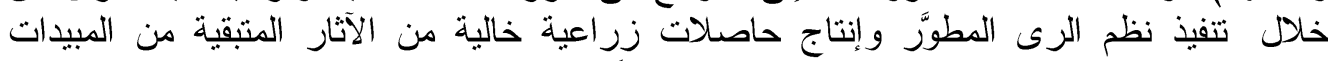

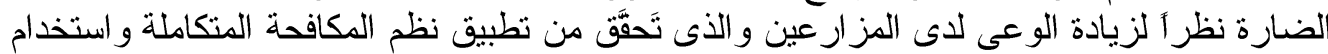

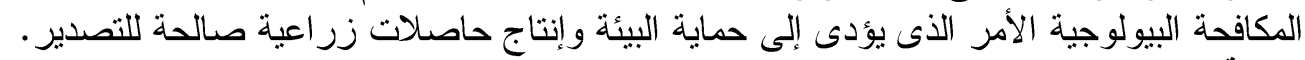
شاملة البحث : مانمان

تضم شاملة البحث جميع المرشدين الزراعيين العاملين بالإزشاد الزراعى الزئ بمحافظة

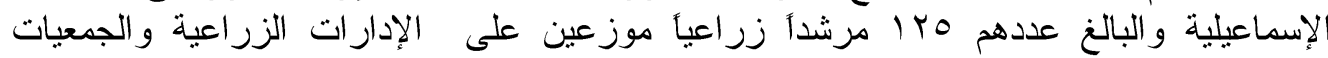

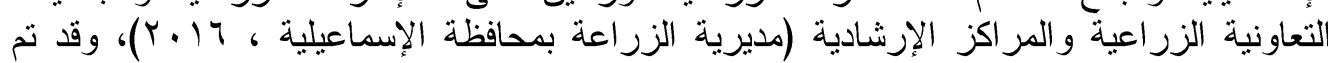

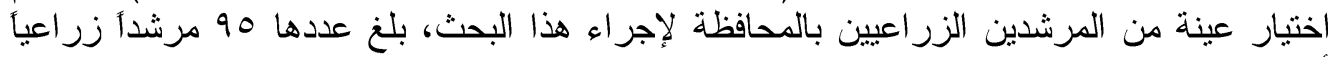

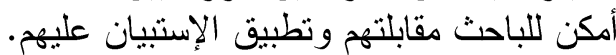
طريقة وأداة جمع البيانات:

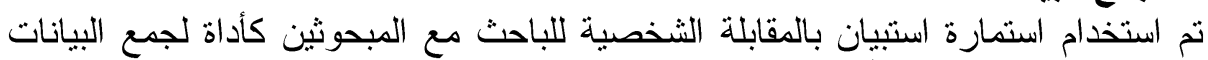

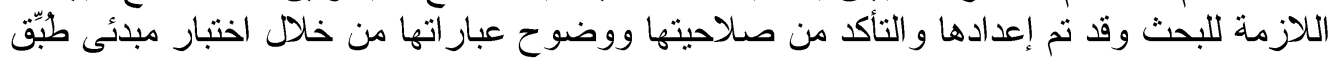

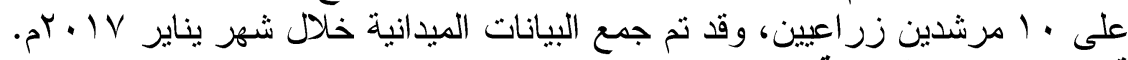

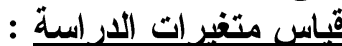
أولاًَ : المتغير متيرات المستقلة المدروسنة.

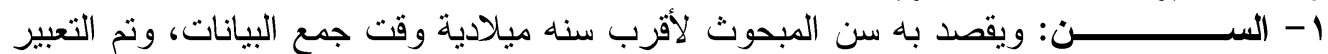

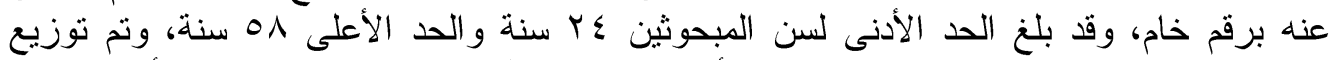

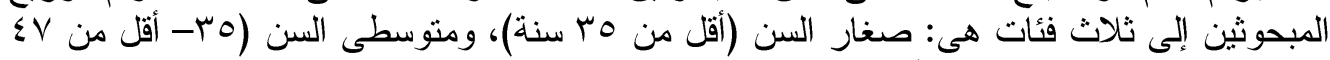

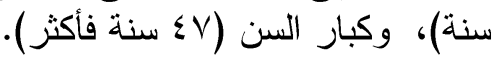

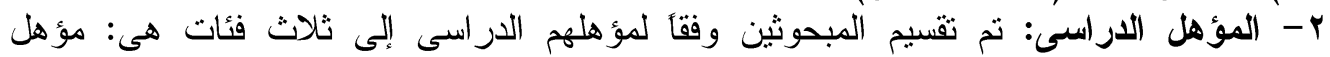

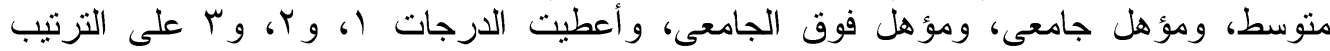
للتزميز

Fayoum J. Agric. Res. \& Dev., Vol. 32, No.2, July, 2018 
Irr

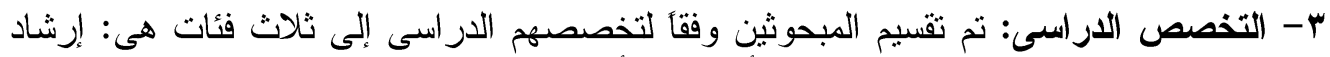

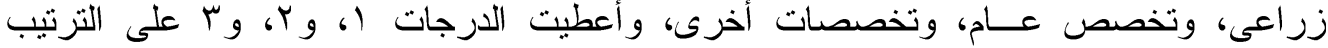

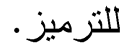

ع - مدة الخدمة فى العمل الزراعى: تم التعبير عنه بالرقم الخام لعدد السنوات التى قضاها المبحوث

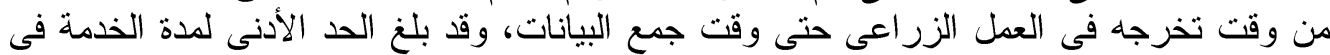

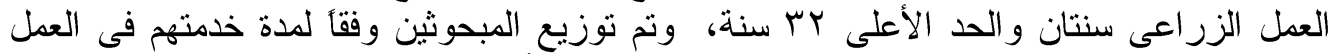

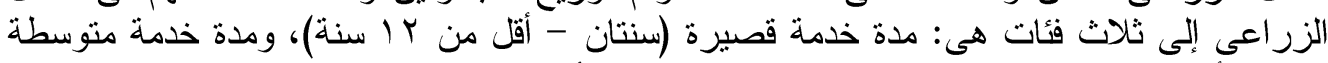

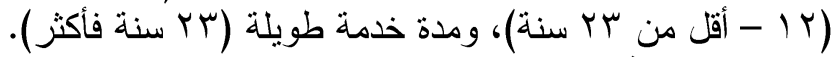

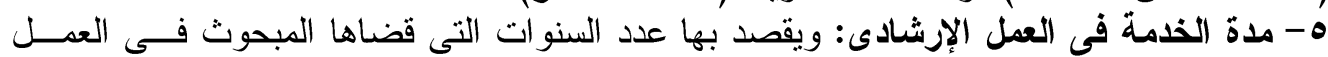

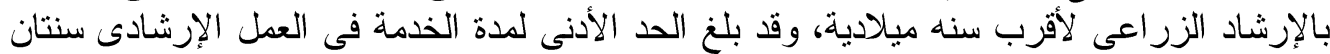

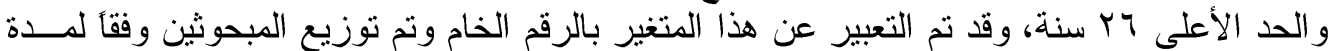

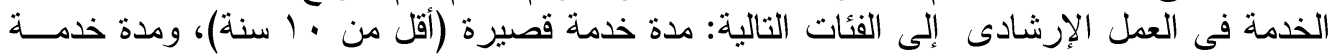

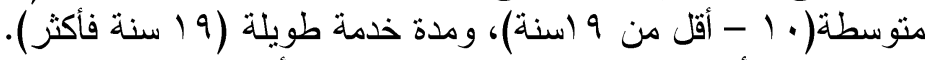

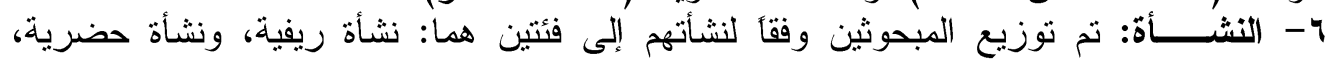

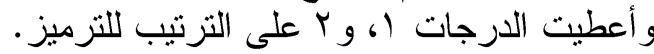

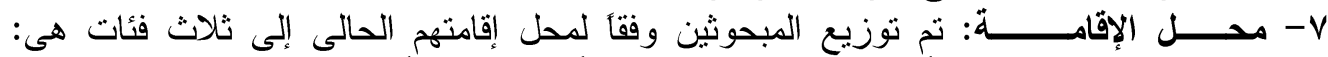

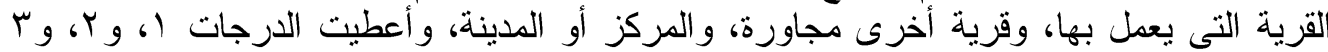

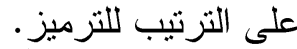

1- الخبرة التتريبية: يقصد بها مجموع ما حضره المرشد أثناء فترة خدمته من دورات تدريبية

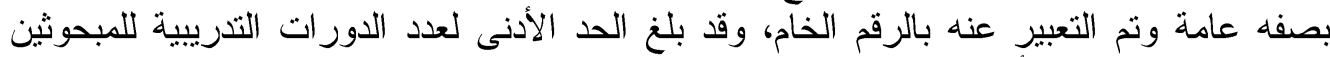

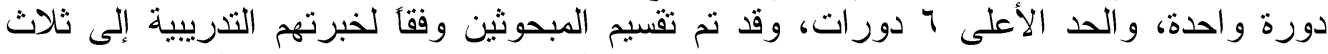

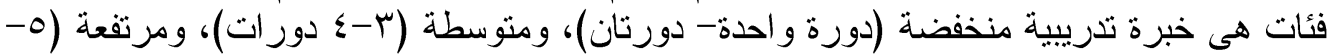
( ب دورات).

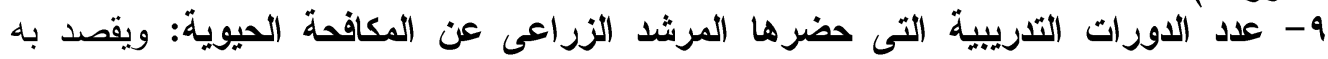

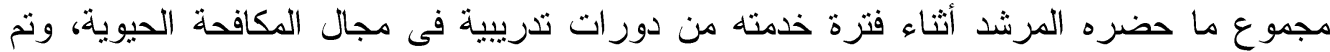

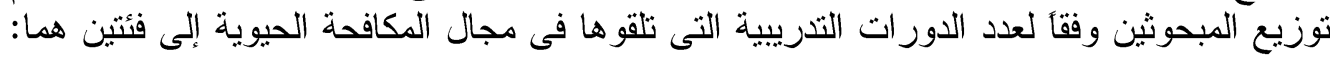

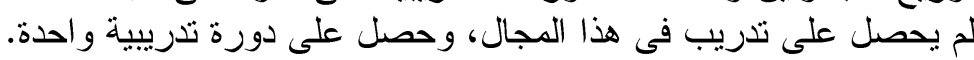

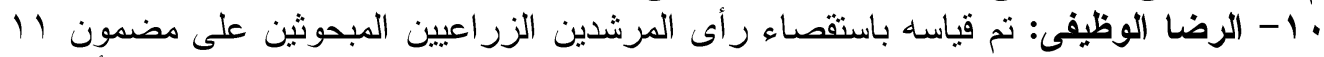

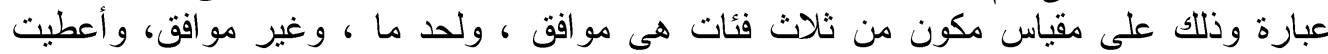

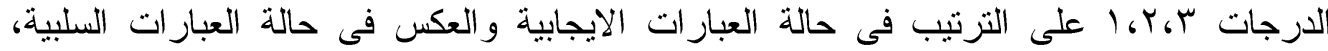

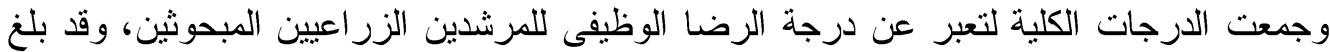

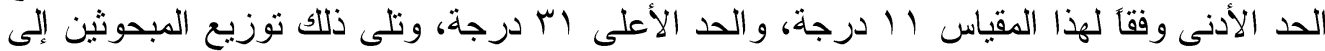

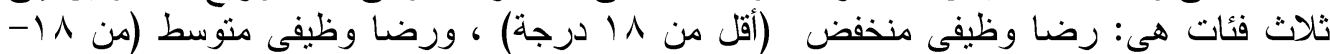

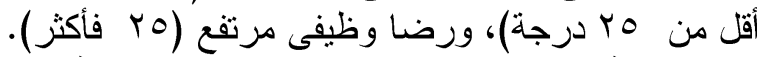

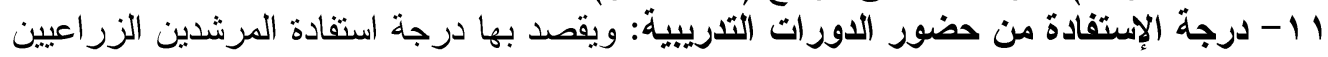

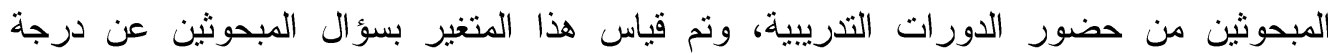

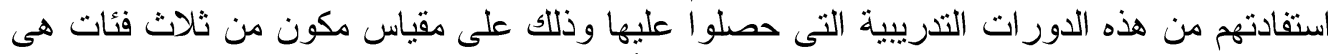

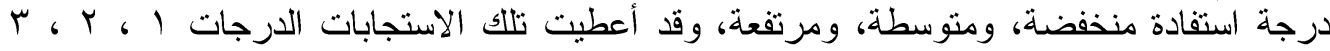

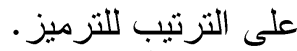

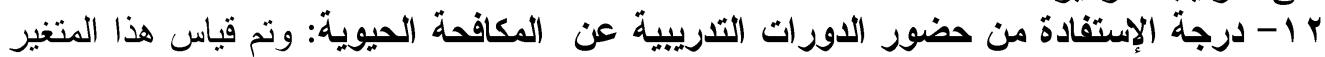

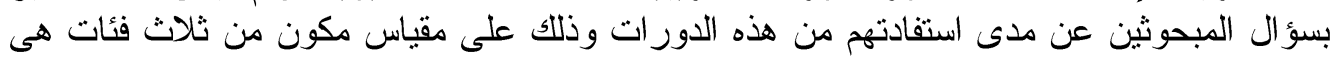

Fayoum J. Agric. Res. \& Dev., Vol. 32, No.2, July, 2018 
I Y

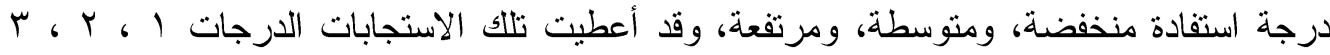

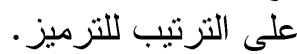

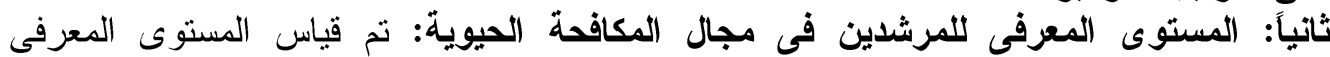

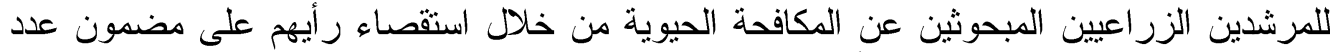

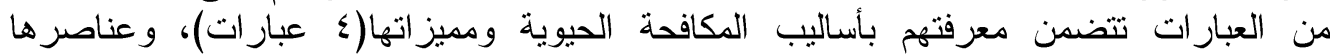

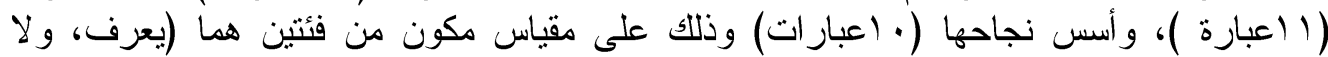

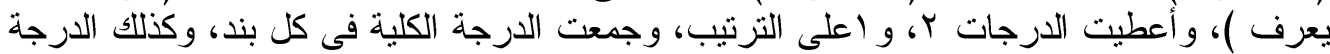

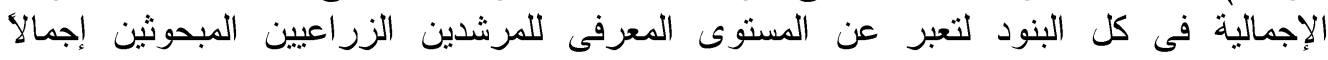
بالمكافحة الحيوية.

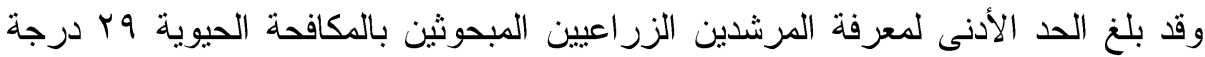
و الحد الأعلى

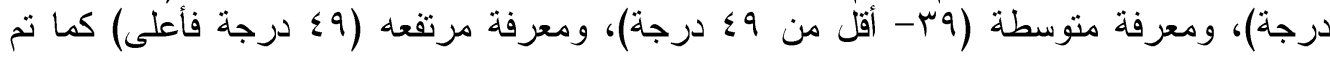

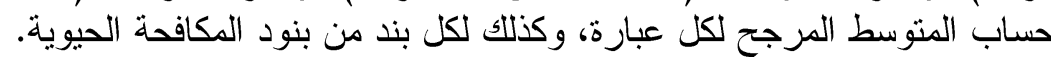

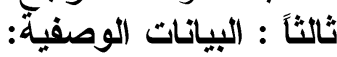

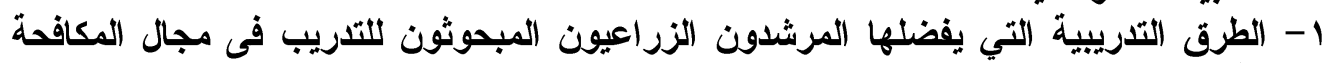

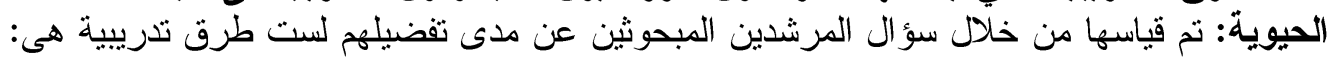

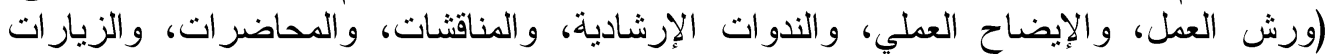

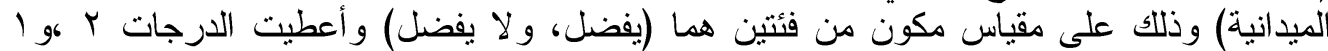

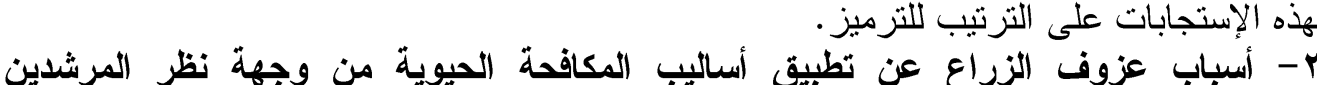

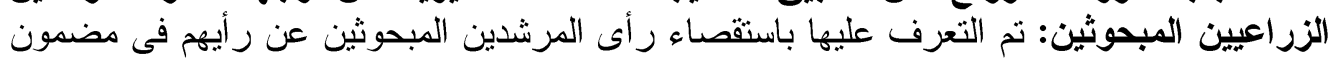

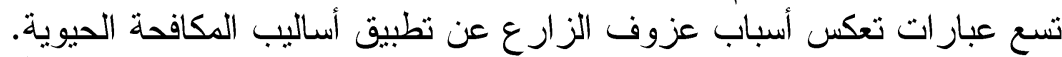

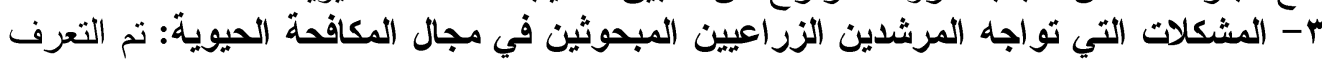

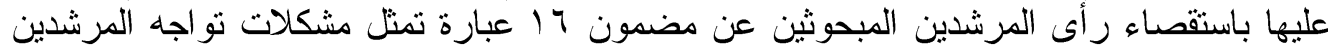
الزراعيين فى مجال المكافحة الحيوية. أدوات التحليل الإحصائى: استخدم فى تحليل البيانات وعرضياتئها التكرارات، و النسب المئوية، و المتوسط الحسابى المرجح، ومعامل الإنى الارنباط البسيط لبيرسون، و اختبار مربع كاى.

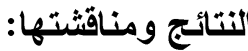

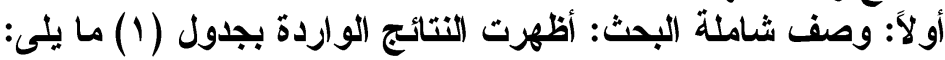

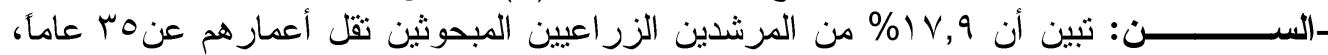

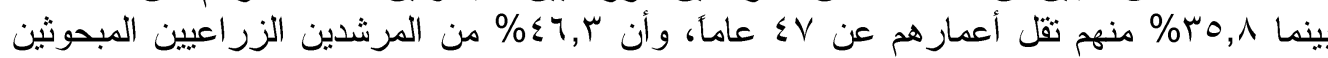

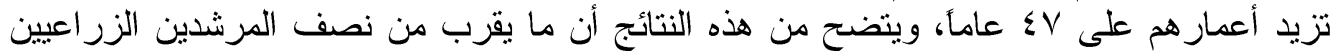

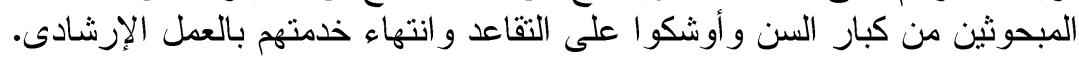

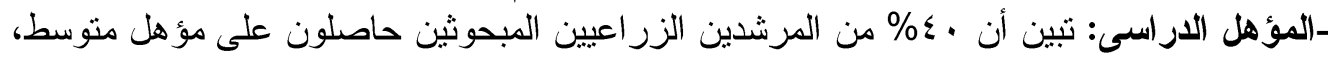

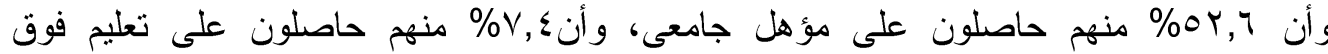

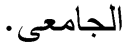
-التخصص الدراسى: تبين أن نسبة ضئيلة جداً (1,1\%) من المرشدين المبحوثين تخصصهم إرشاد

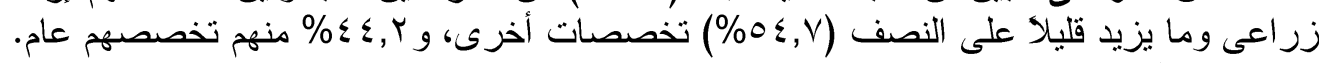

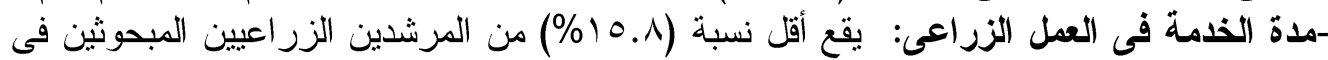

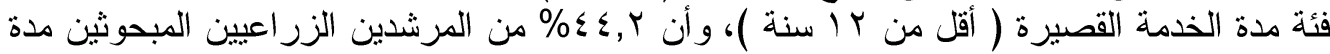

Fayoum J. Agric. Res. \& Dev., Vol. 32, No.2, July, 2018 
iro

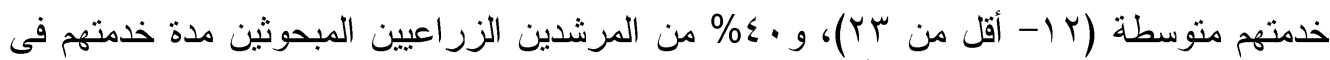

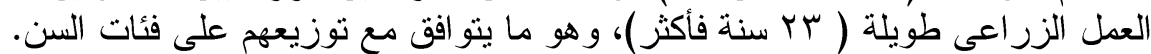

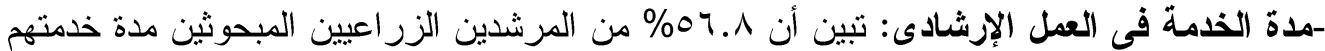

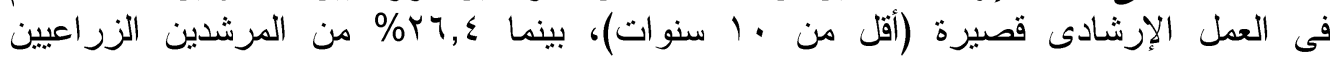

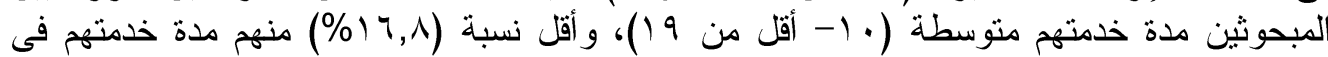

العمل الإرشادى طويلة نسبياً (9 (19 سنة فئه فأكثر).

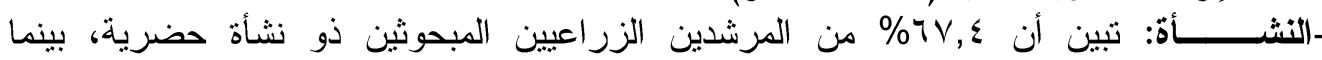

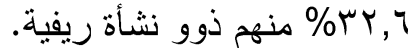
-محل الإقامة: نشير النتائج إلى أن نسبة قليلة جدأ (1,1\%) من المرشدين الزراعينة اعبين المبحوثين

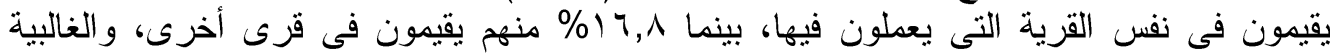

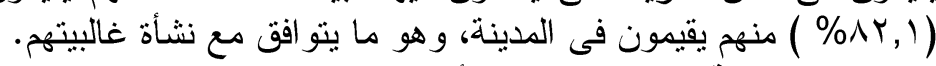

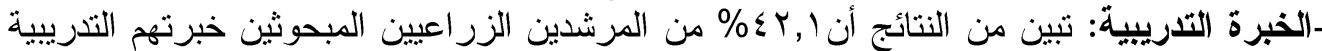

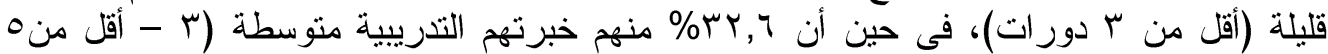

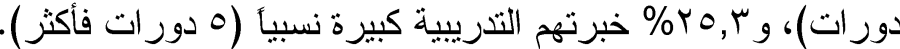

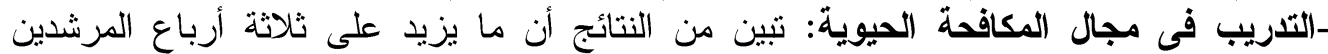

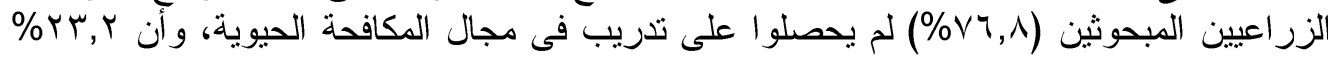
منهم حصلو ا على تدريب في هذا المجال.

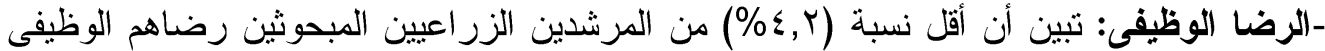

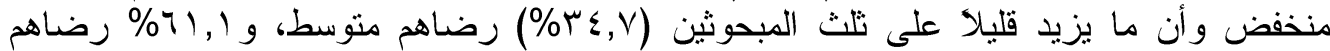

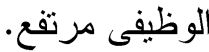
-الاستفادة من الاور ات التهن التدريبية: توضح النتائج الواردة بجدول (ب): أن استفادة المرشدين الزراعيين من الدورات التدريبية التى حصلوا عليها جاءت مرتبة تتازلياً على النحو التالى: وفة التهاً للمتوسط المرجح حيث جاء فى المرنبة الاولى الاستفادة من دورة مكافحة سوسة النخيل بمتوسط دونة

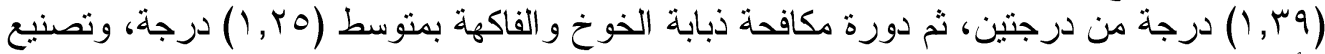

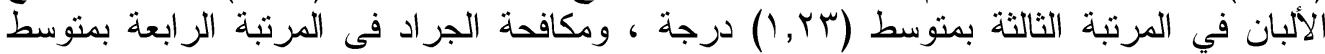

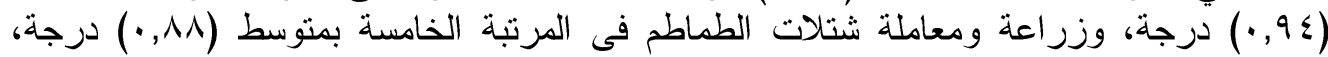

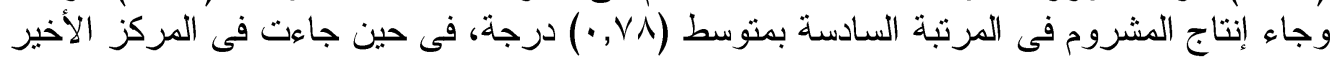

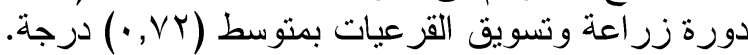

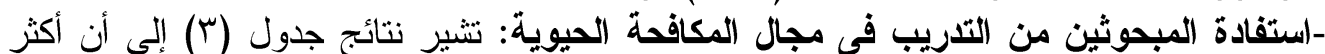

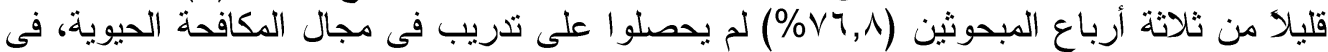

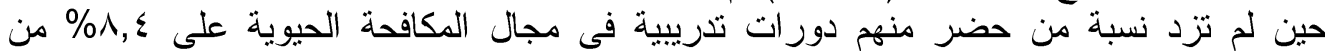

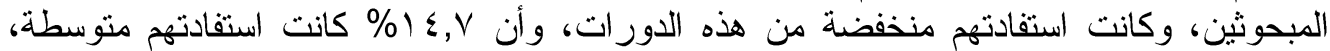
و هو ما يعنى القصور فى تدريب المرشدين الزراعيين المبحوثين فى مجال المكافحة الحيوية،

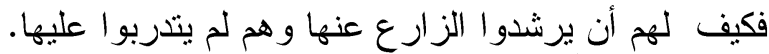

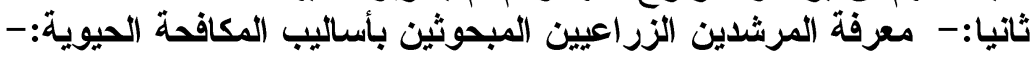

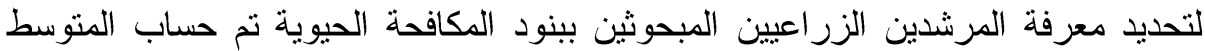

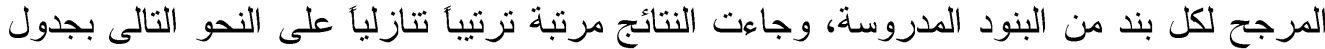

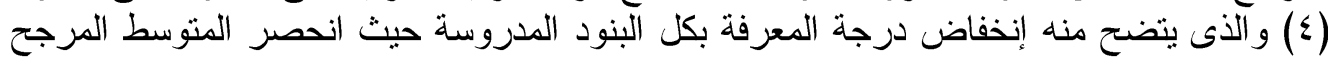

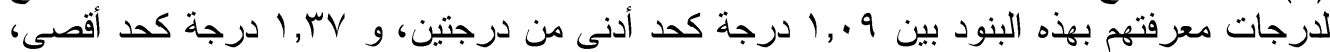

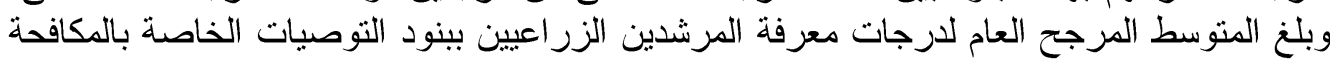

Fayoum J. Agric. Res. \& Dev., Vol. 32, No.2, July, 2018 


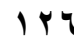

الحيوية r, 1 درجة من درجتين، وجاء ترتيب المعرفة بينود المكافحة الحيوية على النحو التالى وفقاً

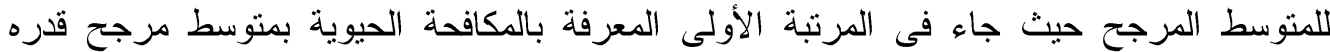

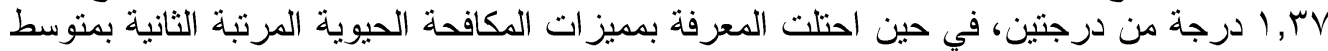

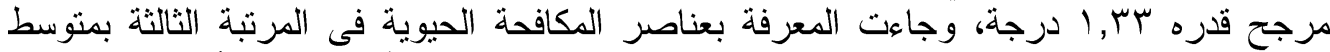

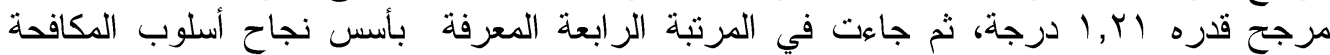

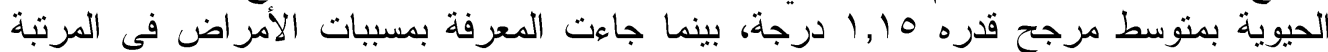

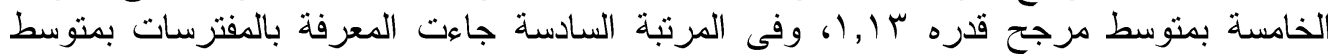

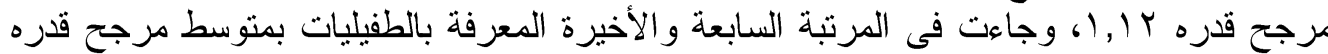

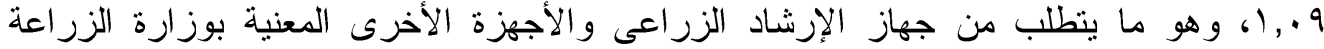

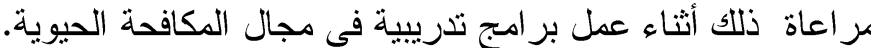

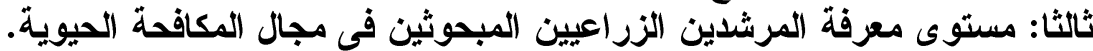

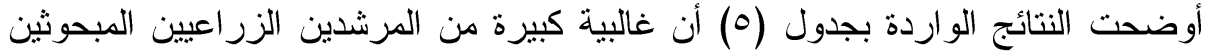

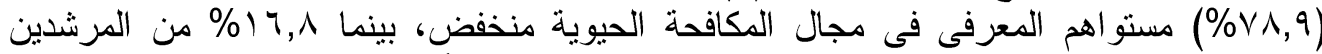

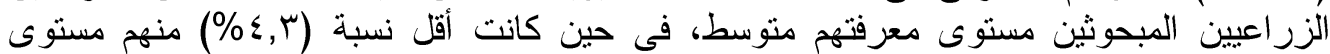

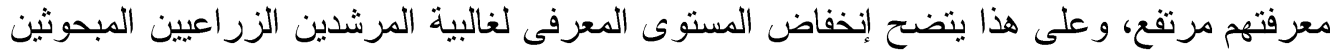

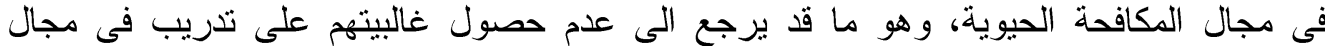

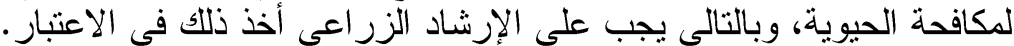

الطرق التدريبية التي يفضلها المرشدون الزراعيون المبحوثئون في مجال المكافحة الحيوية:

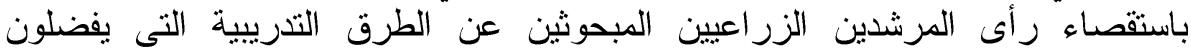

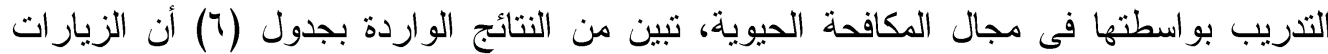

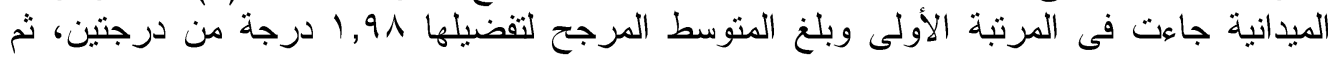

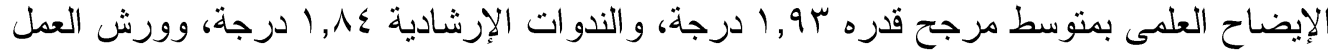

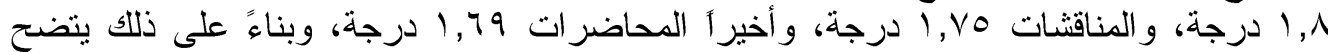

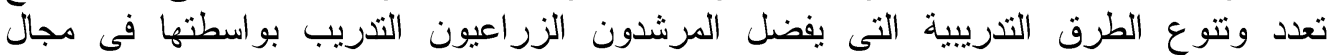

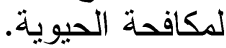
1 - أسباب عزوف الزراع عن استخدام أساليب المكافحة الحيوية من وجهة المرشدين الزراعيين

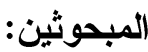

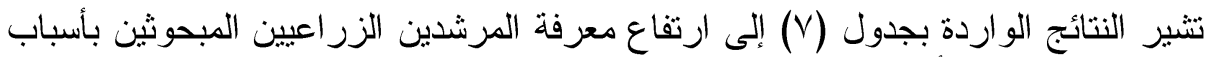

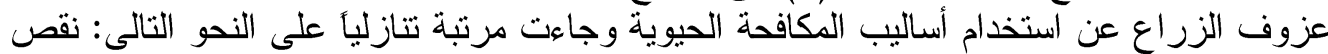

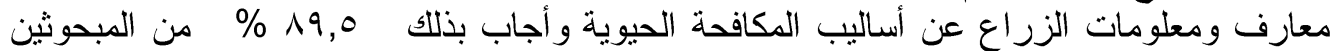

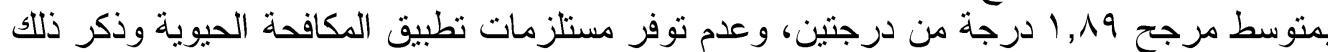

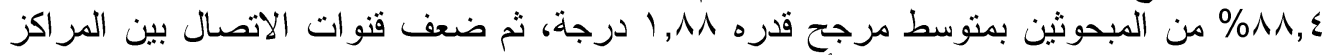

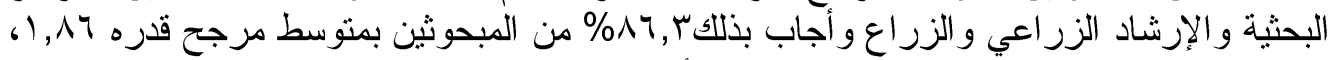

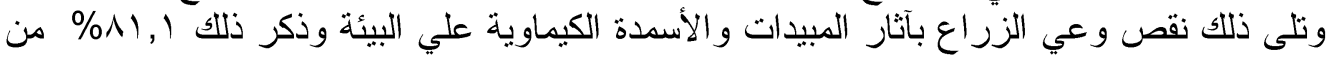

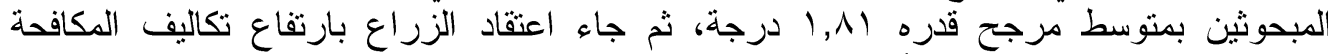

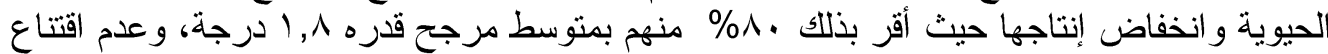

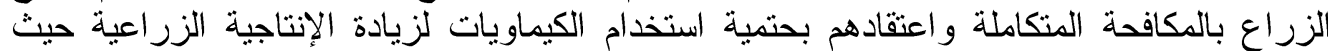

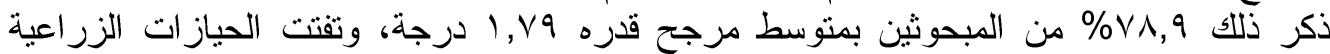

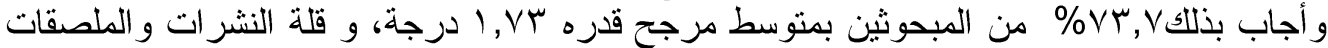

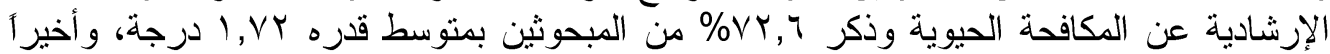

Fayoum J. Agric. Res. \& Dev., Vol. 32, No.2, July, 2018 
IrV

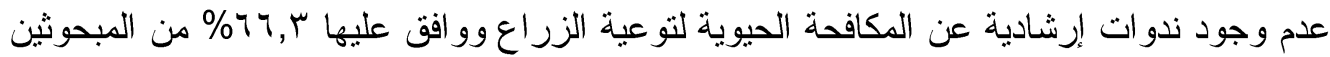

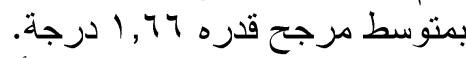

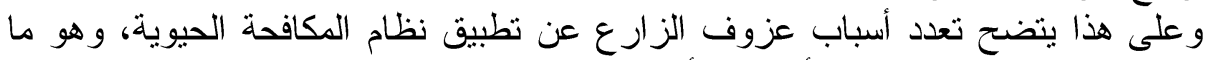

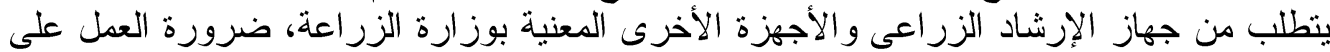

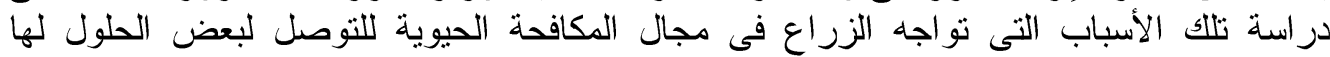

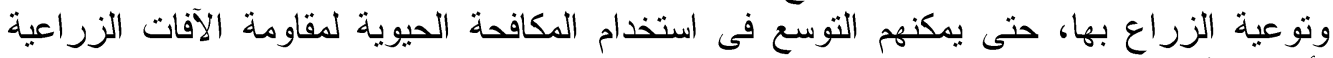

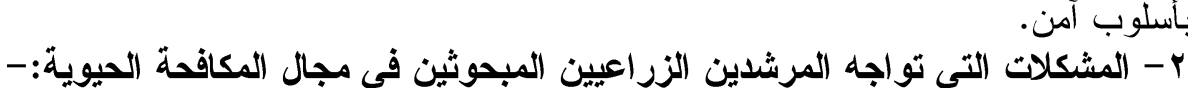

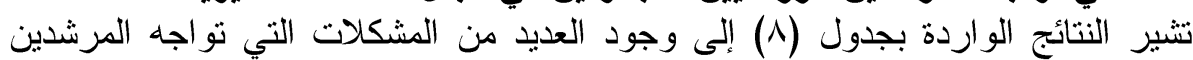

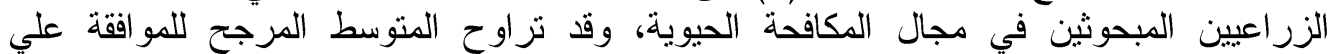

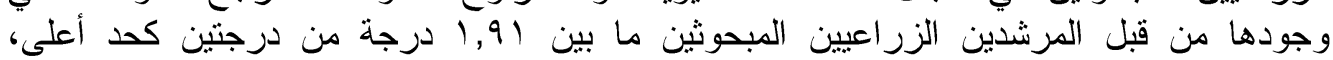

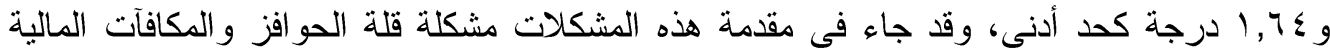

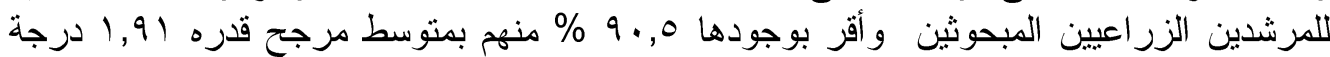

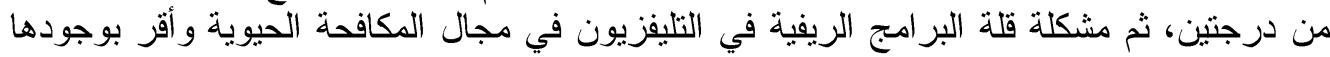

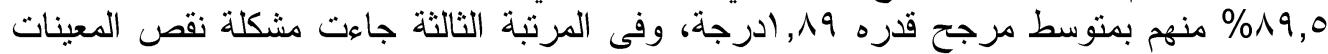

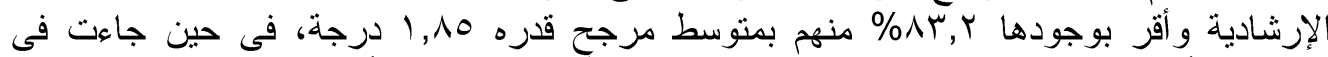

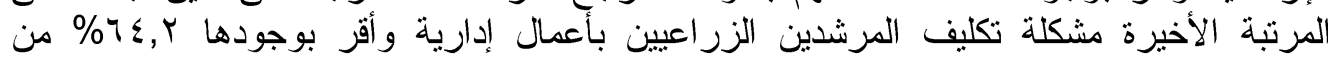

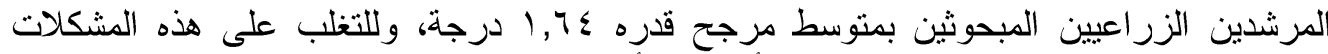

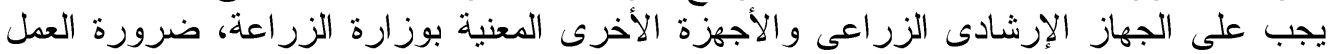

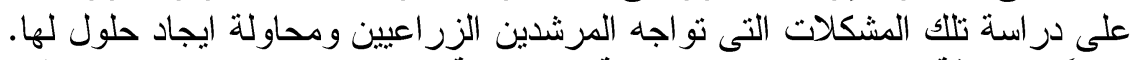

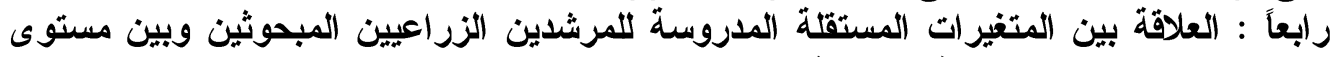

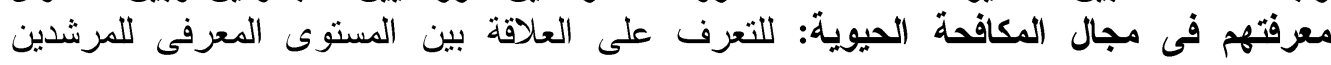

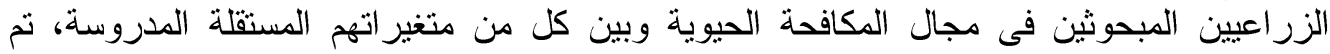

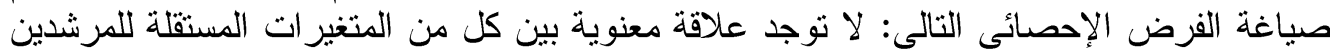

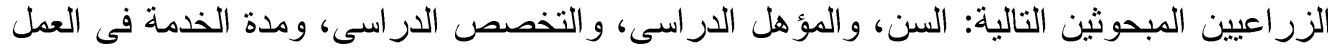

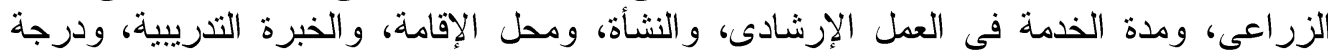

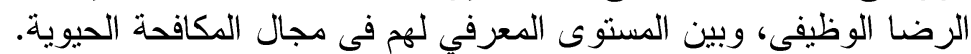

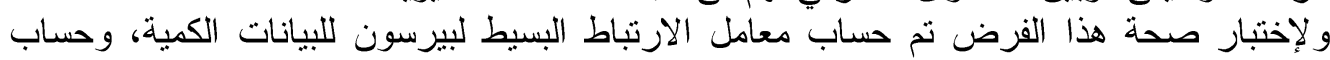

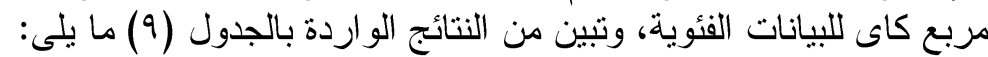

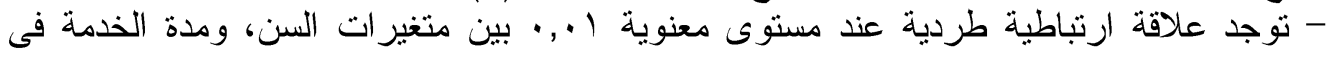

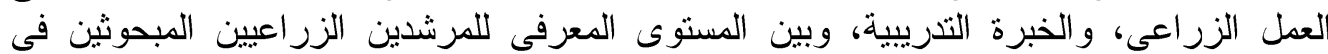

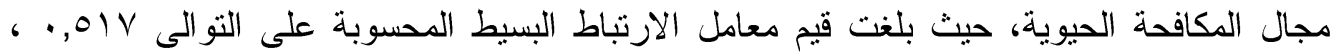

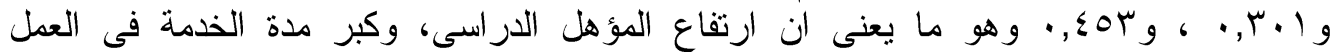

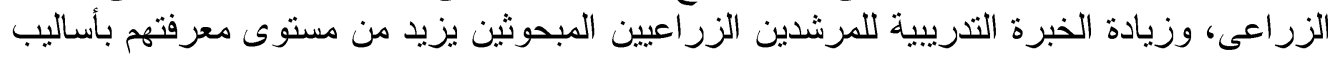

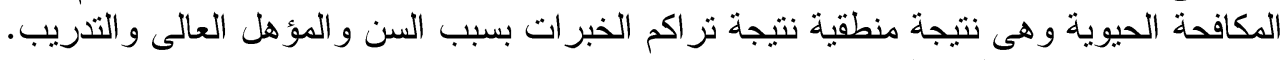

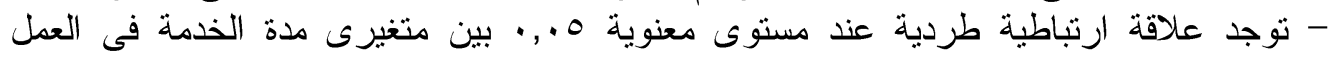

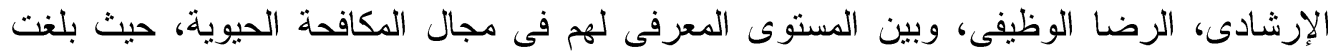

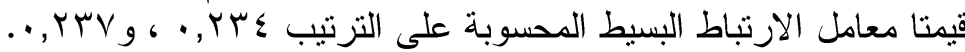

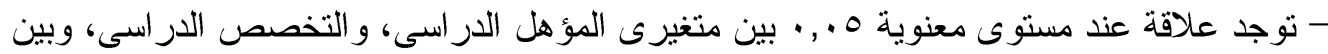

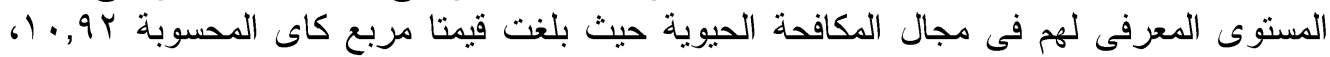

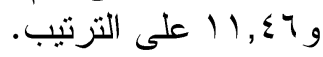

Fayoum J. Agric. Res. \& Dev., Vol. 32, No.2, July, 2018 
I $\mathrm{Y}$

وبناءً على هذه النتائج فإنه لم نتمكن من رفض الفرض الإحصائى السابق كليه، بل يمكن رفضه فقط

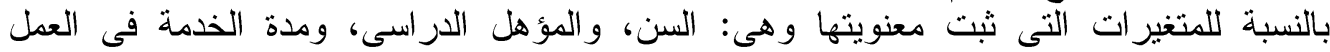

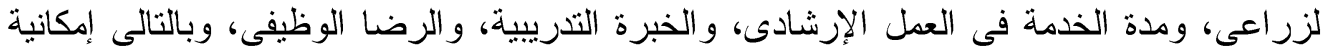

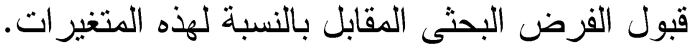
جدول (1): توزيع المرشدين الزراعيين المبحوثين وفقاً لمتغير اتهم المستقلة المدروسة.

\begin{tabular}{|c|c|c|c|c|c|}
\hline \multicolumn{2}{|c|}{ إجمالي المبحوثين } & المتغير ات المستقلة & \multicolumn{2}{|c|}{ إجمالي المبحوثين } & المتغير ات المستقلة \\
\hline$\%$ & العداد & ب - المؤهل الاراسى & $\%$ & العدد & إل السن \\
\hline$\varepsilon$. & $r \wedge$ & متوسط. & $1 V, 9$ & IV & (أقل من هار السننة). \\
\hline OY, 1 & •. & 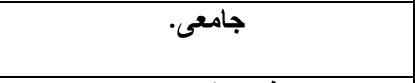 & $r \bullet, \Lambda$ & $r \varepsilon$ & 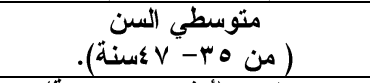 \\
\hline $\mathrm{V}, \varepsilon$ & $\mathrm{V}$ & فوق الجامعى. & $\varepsilon \uparrow, r$ & $\varepsilon \varepsilon$ & كبار السن (أكثر من V عـنة). \\
\hline \multicolumn{3}{|c|}{ ع - مدة الخدمة في العمل الزراعى } & \multicolumn{3}{|c|}{ ب r- التخصص الار اسى } \\
\hline 10,1 & 10 & مدة الخدمة صغيرة (أقل من Y I سنة). & 1,1 & 1 & إرشاد زراعى. \\
\hline$\varepsilon \varepsilon, r$ & $\varepsilon r$ & 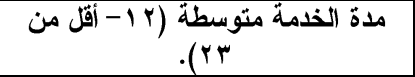 & $\varepsilon \varepsilon, r$ & $\varepsilon r$ & تخصص عام. \\
\hline$\varepsilon$. & $r \Lambda$ & مدة الخدمة كبيرة (Tr سنة فأكثر). & $0 \varepsilon, V$ & or & تخصصات أخرى. \\
\hline \multicolumn{3}{|c|}{ 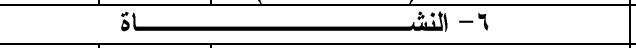 } & \multicolumn{3}{|c|}{ هـ - مدة الخدمة فى العمل الإرشادى } \\
\hline TV, & $7 \varepsilon$ & حضرى & $\Delta 4, \Lambda$ & $0 \varepsilon$ & مدة الخدمة صغيرة \\
\hline \multirow[t]{2}{*}{ rY, } & \multirow[t]{2}{*}{$m$} & \multirow[t]{2}{*}{ ريفى } & Y Y, \& & ro & 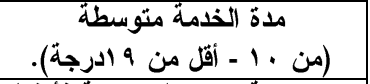 \\
\hline & & & 17,1 & 17 & مدة الخدمة كبيرة (9 (19 سنة فأكثر). \\
\hline \multicolumn{3}{|r|}{ 1- الخبرة التتريبة } & \multicolumn{3}{|r|}{ 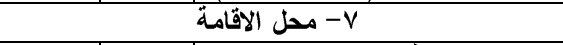 } \\
\hline$\varepsilon r, 1$ & $\varepsilon$. & خبرة صغيرة (أقل من ب دورات). & 1,1 & 1 & نفس القريةة (ثلاث درجات). \\
\hline rY, & rI & خبرة متوسطة (r - أقلّل من ه دورات). & 17,1 & 17 & قرية أخرى (درجتان). \\
\hline$r \Delta, r$ & $r \leq$ & خبرة كبيرة (من ه دورات فأكثر). & $\Lambda r, 1$ & $\mathrm{v \wedge}$ & المدينة (درجة واحدة). \\
\hline \multicolumn{3}{|c|}{ | 1- درجة الرضا الوظيفى } & \multicolumn{3}{|c|}{ 9- التدريب فى مجال المكافحة الحيوية } \\
\hline$\varepsilon, Y$ & $\varepsilon$ & رضا وظيفى منخفض (أقل من ^ الدرجة) & $\vee \vee, \Lambda$ & Vr & لم يحصل على تلدريب. \\
\hline$r \varepsilon, V$ & $r r$ & 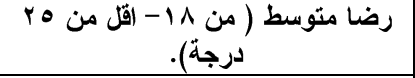 & \multirow[t]{2}{*}{ rr, } & \multirow[t]{2}{*}{ rY } & \multirow[t]{2}{*}{ حضر دورة واحدة. } \\
\hline 71,1 & $0 \wedge$ & رضا وظيفى كبير(0 ب فاكثر). & & & \\
\hline & & & & & ن = 90 مبحوث. \\
\hline
\end{tabular}

جدول (ץ): توزيع المرشدين الزراعيين المبحوثين وفقاً لاستفادتهم من الدورات التدريبية التى حصلوا عليها.

\begin{tabular}{|c|c|c|c|}
\hline$\%$ & العدد & مستوى الإستفادة & r \\
\hline VY.A & $V T$ & لم يحصل على تدريب. & 1 \\
\hline$\Lambda, \xi$ & $\Lambda$ & استقادة منخفضة. & $r$ \\
\hline $1 \leqslant, \wedge$ & $1 \varepsilon$ & استفادة متوسطة. & $\mu$ \\
\hline $1 \ldots$ & 90 & الإجمالي. & $\varepsilon$ \\
\hline
\end{tabular}

Fayoum J. Agric. Res. \& Dev., Vol. 32, No.2, July, 2018 
1 i 9

جدول (r): توزيع المرشدين الزراعيين المبحوثين وفقاً لمستوى استفادتهم من التدريب فى مجال المكافحة الحيوية للآقات الزراعينة الميتوبن

\begin{tabular}{|c|c|c|c|c|c|c|c|c|c|c|c|c|c|}
\hline \multirow[t]{2}{*}{ التزتيب } & \multirow{2}{*}{ المرجح } & \multicolumn{2}{|c|}{ المجموع } & \multicolumn{2}{|c|}{ عالى } & \multicolumn{2}{|c|}{ متوسط } & \multicolumn{2}{|c|}{ منخفض } & \multicolumn{2}{|c|}{ لم يحصل } & \multirow{2}{*}{ مستوى الإستفادة } & \\
\hline & & $\%$ & تكرار & $\%$ & تكرار & $\%$ & تكرار & $\%$ & تكرار & $\%$ & تكرار & & \\
\hline 1 & 1,49 & $1 \ldots$ & 90 & $v, \varepsilon$ & $\mathrm{v}$ & or, $v$ & 01 & 9,0 & 9 & rq,o & $\varepsilon \Lambda$ & مكافحة سوسة النخيل & 1 \\
\hline $\bar{Y}$ & $1, r_{0}$ & $1 \cdots$ & 90 & $\varepsilon, r$ & $\varepsilon$ & $0 Y, 1$ & 0. & $V, \varepsilon$ & $\bar{v}$ & $r \theta, \Lambda$ & $r \Lambda$ & مكافحة ذبابةٌ الذوخ و الفاكهة & $r$ \\
\hline$\xi$ &., $9 \leqslant$ & $1 \ldots$ & 90 & 1,1 & $T$ & $\varepsilon 1,1$ & $\varepsilon 9$ & $\Lambda, \xi$ & $\Lambda$ & $\$ 9,0$ & $\varepsilon V$ & مكافحةٌ الجر اد & $r$ \\
\hline$\mu$ & $1, \pi \mu$ & $1 \ldots$ & 90 & $\overline{7, \mu}$ & 7 & $\varepsilon r, r$ & $\xi 1$ & $1 v, 9$ & IV & rY, T & $\mu$ & تصنيع الالبان & $\varepsilon$ \\
\hline 7 & $\cdot, \mathrm{VA}$ & $1 \ldots$ & 90 & $r, r$ & $\mu$ & $r 4, r$ & ro & $1 v, 9$ & IV & Or, 1 & 0. & انتاج المشروم & 0 \\
\hline 0 & $\cdot, \wedge \wedge$ & $1 \cdots$ & 90 & $\mu, r$ & $r$ & $r \mu, v$ & rr & 11,4 & 11 & 01,7 & $\varepsilon 9$ & زر اعة ومعاملة شتَلات & 7 \\
\hline $\mathrm{v}$ & 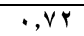 & $1 \ldots$ & 90 & $r, r$ & $r$ & $r \varepsilon, Y$ & Tr & $1+, v$ & 14 & $8 \wedge, 9$ & 04 & زر اعة وتسويق القرعيات & $\mathrm{v}$ \\
\hline
\end{tabular}

جدول (ع): توزيع المرشدين الزراعيين المبحوثين وفقا لمعرفتهم بأساليب المكافحة الحيوية ل تلآقات الزر اعية.

\begin{tabular}{|c|c|c|c|c|c|c|c|c|c|}
\hline \multirow{2}{*}{ الترتيب } & \multirow{2}{*}{ المرجح } & \multicolumn{2}{|c|}{ المجموع } & \multicolumn{2}{|c|}{ يعرف } & \multicolumn{2}{|c|}{ لا يعرف } & \multirow[b]{2}{*}{ بنود المكافحة } & \multirow{2}{*}{ م } \\
\hline & & $\%$ & العدد العد & $\%$ & 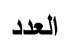 & $\%$ & 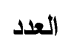 & & \\
\hline 1 & $1, r v$ & $1 \ldots$ & 90 & M & ro & $\pi, r$ & 7. & تعريف المكافحة الحيوية. & 1 \\
\hline$r$ & 1, & $1 \cdots$ & 90 & $r r, V$ & ru & $74, r$ & Tr & مميزات المكافحة الحيوية. & $r$ \\
\hline$r$ & $1, r_{1}$ & $1 \ldots$ & 90 & Y I, & $r$. & $\vee \wedge, q$ & vo & عناصر المكافحة الحيوية. & $r$ \\
\hline $\mathrm{v}$ & $1, .9$ & $1 \ldots$ & 90 & 9,0 & 9 & $9 \cdot, 0$ & 14 & الطفيليات. & $\xi$ \\
\hline 7 & $1,1 Y$ & $1 \ldots$ & 90 & 11,7 & 11 & $\Lambda \Lambda, \xi$ & $\Lambda \varepsilon$ & المفترسات. & 0 \\
\hline 0 & $1,1 \pi$ & $1 \cdots$ & 90 & $1 Y, 4$ & IT & $\Lambda V, \Sigma$ & NT & مسببات الأمر اض. & 7 \\
\hline$\varepsilon$ & 1,10 & $1 \cdots$ & 90 & $1 \leq, V$ & $1 \varepsilon$ & $\Lambda 0, r$ & Al & أسس نجاح أسلوب المكافحة الحيوية. & $\mathrm{v}$ \\
\hline
\end{tabular}

جدول (•): توزيع المرشدين الزراعيين المبحوثين وفقا لمستواهم المعرفى بأساليب المقاومة الحيويةٌ للاقفات الزراعينة.

\begin{tabular}{|c|c|c|c|}
\hline$\%$ & 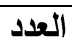 & المستوى المعرفى & م \\
\hline$\vee \wedge, 9$ & vo & منخفض (أقل من q س درجة). & 1 \\
\hline 17,1 & 17 & متوسط (q ب - أقل من q ؛ درجة). & $r$ \\
\hline$\varepsilon, r$ & $\varepsilon$ & مرتفع (9 د درجة فأكثر). & $\mu$ \\
\hline $1 \ldots$ & 90 & سالّى & $\varepsilon$ \\
\hline
\end{tabular}

Fayoum J. Agric. Res. \& Dev., Vol. 32, No.2, July, 2018 
$1 \%$.

جدول (†): توزيع المرشدين الزراعيين المبحوثين وفقاً للطرق التدريبية التي يفضلون التدريب عليها فى مجال المكافحة الحيوية.

\begin{tabular}{|c|c|c|c|c|c|c|c|c|c|}
\hline \multirow[t]{2}{*}{ الترتيب } & \multirow{2}{*}{ المرجح } & \multicolumn{2}{|c|}{ المجموع } & \multicolumn{2}{|c|}{ لايفضلها } & \multicolumn{2}{|c|}{ يفضها } & \multirow[t]{2}{*}{ الطرق التدريبية } & \multirow[b]{2}{*}{ م } \\
\hline & & $\%$ & العدد & $\%$ & العدد & $\%$ & العدد & & \\
\hline 1 & 1,91 & $1 \cdots$ & 90 & $Y, 1$ & $r$ & $9 \vee, 9$ & $9 \pi$ & الزيارات الميدانية & 1 \\
\hline r & $1,9 \pi$ & $1 \ldots$ & 90 & $V, \xi$ & $V$ & $9 r, 7$ & $\wedge \wedge$ & الايضاح العملى & $r$ \\
\hline$\mu$ & $1, \wedge \varepsilon$ & $1 \ldots$ & 90 & 10,1 & 10 & $\wedge \varepsilon, Y$ & $\Lambda$. & الندوات الارشادية & $r$ \\
\hline 0 & 1,10 & $1 \ldots$ & 90 & $r O, r$ & $r \xi$ & $V \leqslant, V$ & V) & المناقششات & $\varepsilon$ \\
\hline 7 & 1,79 & $1 \cdots$ & 90 & $r \cdot, 0$ & rq & 79,0 & 79 & المحاضر ات & 0 \\
\hline$\xi$ & $1, \wedge$. & $1 \ldots$ & 90 & $r$. & 19 & $\Lambda$. & VT & ورش العمل & 7 \\
\hline
\end{tabular}

جدول (V): توزيع المرشدين الزراعيين المبحوثين وفقا لرأيهم فى أسباب عزوف الزراع عن تطبيق أساليب المكافحة الحيوية.

\begin{tabular}{|c|c|c|c|c|c|c|c|c|c|}
\hline \multirow[b]{2}{*}{ الترتيب } & \multirow[b]{2}{*}{ 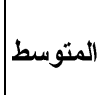 } & \multicolumn{2}{|c|}{ 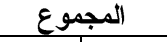 } & \multicolumn{2}{|c|}{ غير موجودة } & \multicolumn{2}{|c|}{ 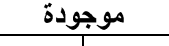 } & \multirow[b]{2}{*}{ الأســـــــــــــــاب } & \multirow{2}{*}{ م } \\
\hline & & $\%$ & 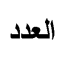 & $\%$ & 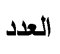 & $\%$ & 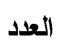 & & \\
\hline 1 & $1, \wedge 9$ & $1 \ldots$ & 90 & $1 \cdot, 0$ & 1. & $\wedge 9,0$ & ^॰ & نقص معارف ومعلومات الزراع عن أساليب & 1 \\
\hline $\mathrm{V}$ & $1, \mathrm{VH}$ & $1 \ldots$ & 90 & $r \bar{r} r$ & ro & $\mathrm{Vr}, \mathrm{V}$ & $\mathrm{V} \cdot$ & تقتت الحياز ات الزراعية & $r$ \\
\hline 9 & 1,74 & $1 \ldots$ & 90 & $r r, V$ & re & $74, r$ & 8 & عدم وجود ندوات إرشادية عن المراع المكافحة الحيوية & $r$ \\
\hline$\wedge$ & $1, V Y$ & $1 \ldots$ & 90 & $r V, \varepsilon$ & rq & $V Y, Y$ & 79 & قلثة النشر ات و الملصقات الإرشادية عن المكافحة & $\varepsilon$ \\
\hline$\varepsilon$ & $1, \wedge 1$ & $1 \ldots$ & 90 & 11,9 & 11 & $\wedge 1,1$ & VV & نقص وعي الزراعة بآثار المبيدات والأسمدة & $\bullet$ \\
\hline$r$ & $1, \wedge \uparrow$ & $1 \ldots$ & 90 & $1 \mathrm{r}, \mathrm{V}$ & ir & $\wedge \uparrow, r$ & Ar & ضعف قتوات الاتصال بين المراكز البحثية & 1 \\
\hline r & $1, \wedge \wedge$ & $1 \ldots$ & 90 & 11,7 & 11 & $\wedge \wedge, \varepsilon$ & $\wedge \varepsilon$ & عدم توفر مستلزمات تطبيق المكافحة الحيوية & $v$ \\
\hline 7 & $1, \vee 9$ & $1 \ldots$ & 90 & $r 1,1$ & $r \cdot$ & $\vee \wedge, q$ & vo & 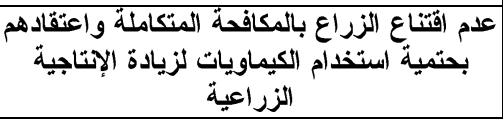 & $\wedge$ \\
\hline
\end{tabular}

Fayoum J. Agric. Res. \& Dev., Vol. 32, No.2, July, 2018 
$|r|$

جدول (^): توزيع المرشدين المبحوثين وفقا لرأيهم فى وجود مشكلات تواجههم في مجال المكافحة الحيوية.

\begin{tabular}{|c|c|c|c|c|c|c|c|c|c|}
\hline \multirow[b]{2}{*}{ الترتيب } & \multirow{2}{*}{ المتوسط } & \multicolumn{2}{|c|}{ 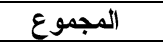 } & \multicolumn{2}{|c|}{ غير موجودة } & \multicolumn{2}{|c|}{ موجودة } & \multirow[b]{2}{*}{ الأســــــــــــــاب } & \multirow{2}{*}{ م } \\
\hline & & $\%$ & العدد & $\%$ & العدد & $\%$ & العدد & & \\
\hline $\mathrm{v}$ & $1, \mathrm{VV}$ & $1 \ldots$ & 90 & rr, r & YY & $V \square, \Lambda$ & $V^{r}$ & نقص الامكانيات المادية للعمل الارشادي. & 1 \\
\hline D & $1, \wedge 1$ & $1 \ldots$ & 90 & 11,9 & 11 & $\Lambda 1,1$ & VV & تمسك زراع المكافحة الحيويةة بالقديم. & r \\
\hline 11 & $1,7 \wedge$ & $1 \ldots$ & 90 & ri, & r. & $7 \wedge, \varepsilon$ & 10 & تكليف المرشدين بأعمال أخرى. & $r$ \\
\hline 1 & 1,91 & $1 \ldots$ & 90 & 9,0 & 9 & $9 \cdot, 0$ & $\Lambda \mathrm{T}$ & نقص الحوافز و المكافأت المالية للمرشدين & $\varepsilon$ \\
\hline$\varepsilon$ & $1, \wedge r$ & $1 \ldots$ & 90 & 17,1 & 17 & $\Delta r, r$ & $\mathrm{vq}$ & تقلص أعداد المرشدين الزراعيين. & o \\
\hline r & $1, \wedge 9$ & $1 \ldots$ & 90 & $1 \cdot, 0$ & 1. & $\wedge 9,0$ & ^॰ & قلة البرامج الريفية في التليفزيون في الميوية & 7 \\
\hline $\mathrm{v}$ & $1, \mathrm{VV}$ & $1 \ldots$ & 90 & $r r, r$ & rr & $\vee \vee, \wedge$ & Vr & نقص النشر ات الإرشاديةّ عن المكافحة & $\checkmark$ \\
\hline 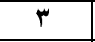 & $1, \wedge \varepsilon$ & $1 \ldots$ & 90 & 17,1 & 17 & $\Lambda T, Y$ & $\Lambda$. & نقص المعينات الإرشادية. & $\Lambda$ \\
\hline 7 & $1, \wedge$ & $1 \ldots$ & 90 & r. & 19 & $\wedge$. & VI & نقص البرامج التلاريبية للمرشدين في الحيوية. & 9 \\
\hline$\varepsilon$ & $1, \wedge r$ & $1 \ldots$ & 90 & $17, \wedge$ & 17 & $\wedge r, r$ & va & للصرش الفترة الزمنيةٌ للاورات التدريبية. & 1. \\
\hline ir & $1,7 \varepsilon$ & $1 \ldots$ & 90 & $r \Delta, \Lambda$ & $r \varepsilon$ & $T \varepsilon, Y$ & 11 & مشاكل إدارية في العمل. & 11 \\
\hline$\wedge$ & $1, v_{0}$ & $1 \ldots$ & 90 & ro,r & $r \varepsilon$ & $V \varepsilon, V$ & $v_{1}$ & ضعف مشاركة الزراعة في الندوات & ir \\
\hline$\varepsilon$ & $1, \wedge r$ & $1 \ldots$ & 90 & 17,1 & 17 & $\Lambda \mu, Y$ & $\mathrm{va}$ & نقص وسائل الإتثال للمرشدين. & ir \\
\hline 9 & $1, v_{1}$ & $1 \ldots$ & 90 & rq,० & rı & $v_{\cdot}, 0$ & iv & تأخر وصول المطبوعات الإرشادية & $1 \varepsilon$ \\
\hline 1. & 1,79 & $1 \ldots$ & 90 & $r \cdot, 0$ & rq & 79,0 & 74 & أمية غالبية المربين. & 10 \\
\hline $\mathrm{V}$ & $1, \mathrm{VV}$ & $1 \ldots$ & 90 & rY,Y & YY & $V Y, \Lambda$ & $v^{\mu}$ & نقص الإمكانيات المادية للعمل الإرشادى. & 17 \\
\hline
\end{tabular}

جدول (9): قيم معاملات الإرتباط للعلاقة بين مستوى معرفة المرشدين الزراعيين فى مجال المكافحة الحيوية وبين متغير اتهم المستقلة المدروسة.

\begin{tabular}{|c|c|c|c|}
\hline 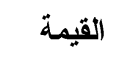 & الأداة الإحصائية المستخدمة & المتغيرات المستقلة المدروسة & \\
\hline$* * 0.597$ & \multirow{5}{*}{ معامل الارتباط البسيط لبيرسون } & السن & 1 \\
\hline$* * 0.301$ & & مدة الخدمة في العمل الزراعى. & r \\
\hline$* 0.234$ & & مدة الخدمة في العمل الإرشادى. & $r$ \\
\hline$* * 0.453$ & & الخبرة التثريبية. & $\varepsilon$ \\
\hline$* 0.237$ & & درجةٌ الرضا الوظيفى. & 0 \\
\hline$* 1 \cdot .9 Y$ & \multirow{4}{*}{ 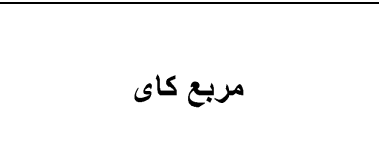 } & المؤهل الدراسى. & 7 \\
\hline$* 11 . \leqslant 4$ & & التخصص الاراسى. & $\mathrm{v}$ \\
\hline 纟.AT- & & النشأة. & $\Lambda$ \\
\hline Y.OY- & & محل الإقامة. & 9 \\
\hline
\end{tabular}

Fayoum J. Agric. Res. \& Dev., Vol. 32, No.2, July, 2018 


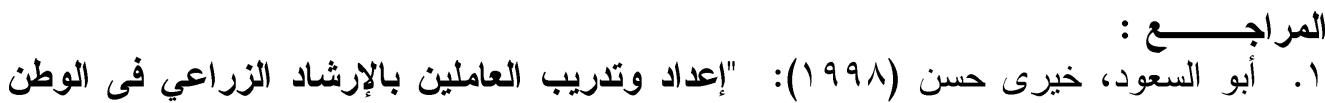

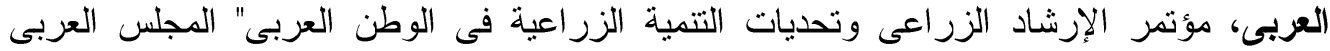

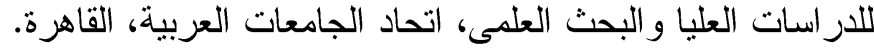

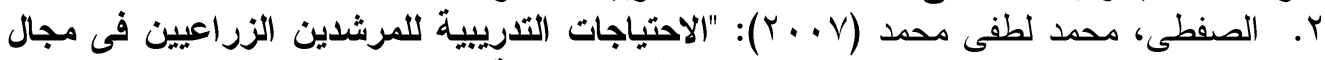

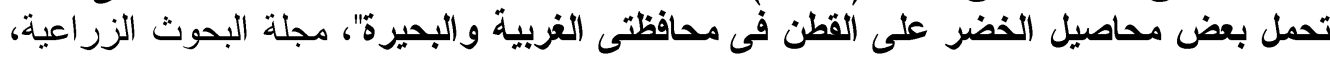

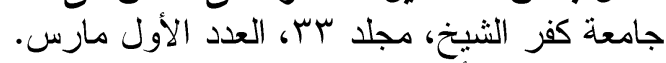

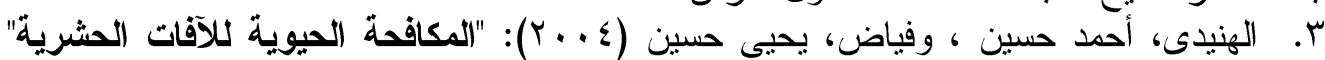

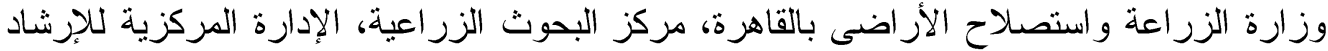

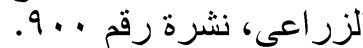

ع. بهلول، أحمد قدرى(1999 1): "أثز التكنولوجيا الكيماوية علي التنمية الزراعية المتواصلة في الزئية

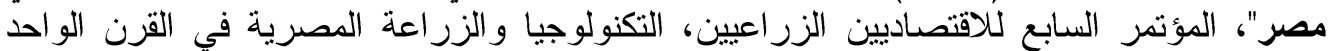

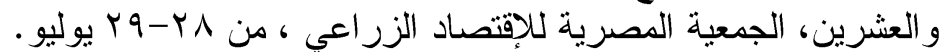

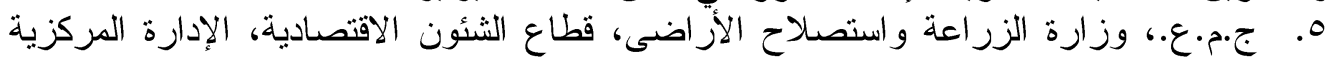

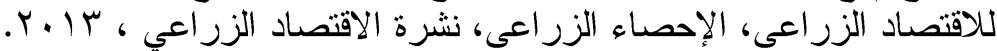

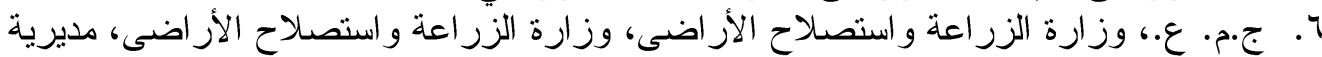

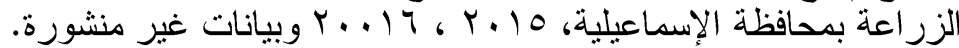

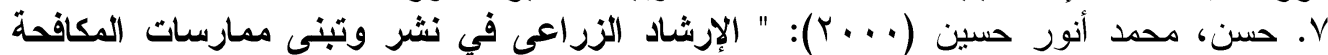

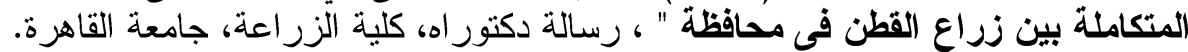

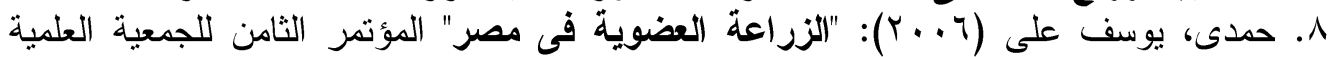

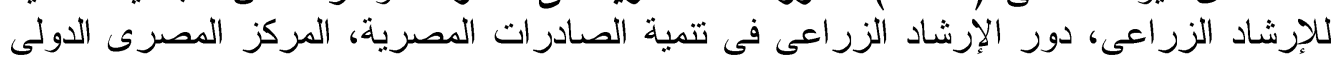

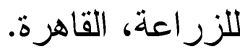

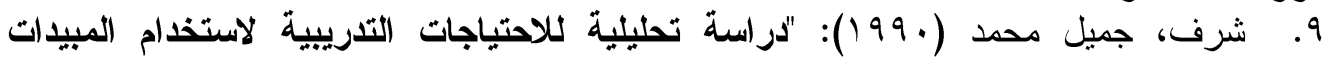

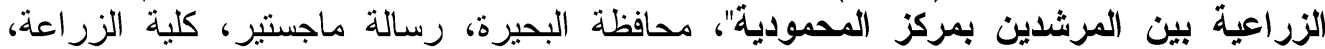
جامعة الإسكندرية.

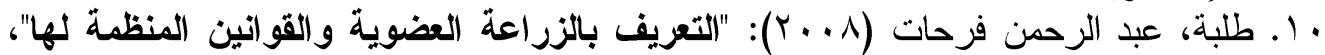

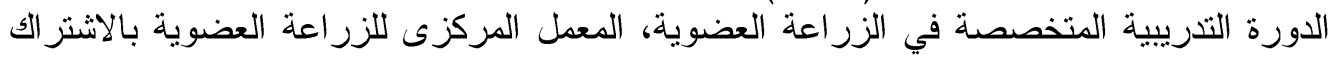

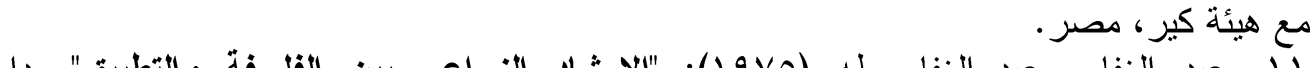
1) أ. عبد الغفار، عبد الغفار طه (9v0 ()): "الإرشاد الزراعى بين القلسفة والتطبيق"، دار المطبو عات الجديدة، الإسكندرية.

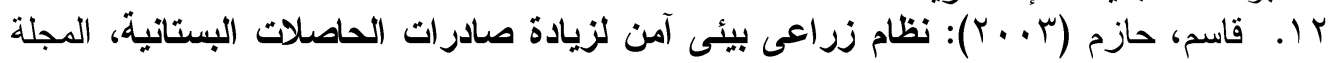

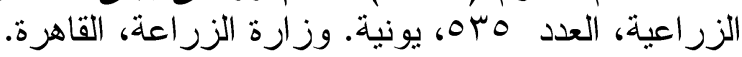

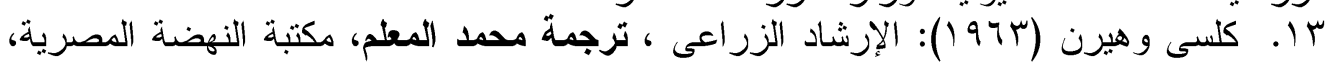

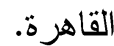

14. Kregice, R.V. and Morgan, D.W. Educational and Psychological Measurement. College Station, Durham, North Carolina, U.S.A. (1970).

15. http://www.capmas.gov.eg/Pages/Publications.aspx?page_id=5104

16. http://www.mwri.gov.eg/project/sinai.aspx

17.http://www.shorouknews.com/news/view.aspx ?cdate $=11022017 \& \mathrm{id}=57 \mathrm{~d} 6 \mathrm{c}$ f3d-0ea1-48fa-b8fa-3c5e9b6da314

18. https://eg.kompass.com,2017

Fayoum J. Agric. Res. \& Dev., Vol. 32, No.2, July, 2018 


\title{
KNOWLEDGE LEVEL OF AGRICULTURAL EXTENSIONISTS IN THE FIELD OF BIOLOGICAL CONTROL IN ISMAILIA GOVERNORATE
}

\author{
Dr. Ismail Ibrahim Hassan Abdullah
}

Department of Agricultural Extension and Rural Sociology

Faculty of Agriculture, Cairo Al-Azhar University

\begin{abstract}
The aim of the research were to determine knowledge level of agricultural Extensionists in the field of Biological Control, identify training methods which preferred by agricultural Extensionists for training in the field of Biological Control, identify reasons for farmers 'reluctance to apply Biological Control methods from the point of view of the Extensionists, and determining the relationship between the studied variables and the knowledge level of the agricultural Extensionists in the field of Biological Control.

Research was conducted on a random sample of 95 agricultural Extensionists in Ismailia Governorate. Data were collected by a questionnaire in January 2017, frequency, percentage, weighted average, Pearson's simple correlation coefficient, Chi square were used to analyse data.

The main findings of the research were as follows:

1. More than three froths of the respondents $(76.8 \%)$ of the agricultural Extensionists did not receive training in the field of Biological Control. 8.4\% and $14.7 \%$ of them had low and average benefit.

2. about four fifths of the respondents (78.9\%) had low knowledge of Biological Control, compared with $4.3 \%$ have high level of knowledge.

3. Agricultural Extensionists prefer the following methods of training in the field of Biological Control: field visits, practical demonstration, and seminars.

4. Reasons of reluctance of farmers to use the Biological Control from the point of view of respondents: Lack of knowledge and information of farmers about the methods of biological control, lack of requirements for the application of biological control, weak shortage of communication challenges between research centers and agricultural extension and farmers.

5. The most important problems faced respondents in the field of biological control were: lack of incentives and rewards, shortage of extension programs on Biological Control, lack of extension aids.

6. There is a significant relationship between the following variables: age, academic qualification, academic specialization, length of service in extension work, training, the degree of job satisfaction, and knowledge level of the extensionists in the field of Biological Control.
\end{abstract}

Fayoum J. Agric. Res. \& Dev., Vol. 32, No.2, July, 2018 